\title{
Interhemispheric Comparisons of Large Nighttime Magnetic Perturbation Events Relevant to GICs
}

\section{Engebretson, Mark J.; Kirkevold, Kathryn R.; Steinmetz, Erik S.; Pilipenko, Viacheslav A.; Moldwin, Mark} B.; McCuen, Brett A.; Clauer, C. R.; Hartinger, Michael D.; Coyle, Shane; Opgenoorth, Hermann Total number of authors:

17

Published in:

Journal of Geophysical Research: Space Physics

Link to article, DOI:

10.1029/2020JA028128

Publication date:

2020

Document Version

Peer reviewed version

Link back to DTU Orbit

Citation (APA):

Engebretson, M. J., Kirkevold, K. R., Steinmetz, E. S., Pilipenko, V. A., Moldwin, M. B., McCuen, B. A., Clauer, C. R., Hartinger, M. D., Coyle, S., Opgenoorth, H., Opgenoorth, H., Willer, A. N., Edwards, T. R., Boteler, D. H., Gerrard, A. J., Freeman, M. P., \& Rose, M. C. (2020). Interhemispheric Comparisons of Large Nighttime Magnetic Perturbation Events Relevant to GICs. Journal of Geophysical Research: Space Physics, 125(8), [e2020JA028128]. https://doi.org/10.1029/2020JA028128

\section{General rights}

Copyright and moral rights for the publications made accessible in the public portal are retained by the authors and/or other copyright owners and it is a condition of accessing publications that users recognise and abide by the legal requirements associated with these rights.

- Users may download and print one copy of any publication from the public portal for the purpose of private study or research.

- You may not further distribute the material or use it for any profit-making activity or commercial gain

- You may freely distribute the URL identifying the publication in the public portal 
Engebretson Mark, J. (Orcid ID: 0000-0002-3882-8108)

Pilipenko Viacheslav A. (Orcid ID: 0000-0003-3056-7465)

Moldwin Mark, B. (Orcid ID: 0000-0003-0954-1770)

Clauer C. Robert (Orcid ID: 0000-0003-2795-822X)

Hartinger Michael, D. (Orcid ID: 0000-0002-2643-2202)

Coyle Shane (Orcid ID: 0000-0003-1730-2753)

Opgenoorth Hermann, J. (Orcid ID: 0000-0001-7573-5165)

Schillings Audrey (Orcid ID: 0000-0001-6968-5405)

Boteler David, H (Orcid ID: 0000-0001-9087-6214)

Gerrard Andrew, J. (Orcid ID: 0000-0002-9626-2085)

Freeman Mervyn, P. (Orcid ID: 0000-0002-8653-8279)

\section{Interhemispheric Comparisons of Large Nighttime Magnetic Perturbation Events Relevant to GICs}

Mark J. Engebretson ${ }^{1}$, Kathryn R. Kirkevold ${ }^{1}$, Erik S. Steinmetz ${ }^{1}$, Viacheslav A. Pilipenko ${ }^{1,2}$, Mark B. Moldwin ${ }^{3}$, Brett A. McCuen ${ }^{3}$, C. R. Clauer ${ }^{4}$, Michael D. Hartinger ${ }^{4,5}$, Shane Coyle ${ }^{4}$, Hermann Opgenoorth ${ }^{6}$, Audrey Schillings ${ }^{6}$, Anna N. Willer ${ }^{7}$, Thom R. Edwards ${ }^{7}$, David H. Boteler $^{8}$, Andy J. Gerrard ${ }^{9}$, Mervyn P. Freeman ${ }^{10}$, and Michael C. Rose ${ }^{10}$

${ }^{1}$ Augsburg University, Minneapolis, MN

${ }^{2}$ Institute of Physics of the Earth, Moscow, Russia

${ }^{3}$ University of Michigan, Ann Arbor, MI

${ }^{4}$ Virginia Tech, Blacksburg, VA

${ }^{5}$ Space Science Institute, Boulder, CO

${ }^{6}$ Umeå University, Umeå, Sweden

${ }^{7}$ DTU Space, Kgs. Lyngby, Denmark

${ }^{8}$ Natural Resources Canada, Ottawa, ON, Canada

${ }^{9}$ New Jersey Institute of Technology, Newark, NJ

${ }^{10}$ British Antarctic Survey, Cambridge, UK

This article has been accepted for publication and undergone full peer review but has not been through the copyediting, typesetting, pagination and proofreading process which may lead to differences between this version and the Version of Record. Please cite this article as doi: 10.1029/2020JA028128 
revised version submitted to the Journal of Geophysical Research - Space Physics June 19, 2020

Key Words: geomagnetically-induced currents, magnetic perturbation events, substorms, magnetic storms, magnetic conjugacy, omega bands

\section{Key Points:}

Conjugate pre-midnight MPEs were largest in $\mathrm{dBx} / \mathrm{dt}$ and were often but not always simultaneous to within 3 min over $\sim 100-700 \mathrm{~km}$ in latitude.

Conjugate post-midnight MPEs were associated with omega bands, often largest in $\mathrm{dBy} / \mathrm{dt}$, very localized, and independent in time over $\sim 1.5 \mathrm{~h}$.

Perturbation amplitudes and maximum derivatives favored a current generator model over a voltage generator model for near-solstice events.
Abstract
Nearly all studies of impulsive magnetic perturbation events (MPEs) with large magnetic field variability $(\mathrm{dB} / \mathrm{dt})$ that can produce dangerous geomagnetically-induced currents (GICs) have used data from the northern hemisphere. Here we present details of four large-amplitude MPE events $(|\Delta \mathrm{Bx}|>900 \mathrm{nT}$ and $|\mathrm{dB} / \mathrm{dt}|>10 \mathrm{nT} / \mathrm{s}$ in at least one component) observed between 2015 and 2018 in conjugate high latitude regions $\left(65-80^{\circ}\right.$ corrected geomagnetic latitude), using magnetometer data from (1) Pangnirtung and Iqaluit in eastern Arctic Canada and the magnetically conjugate South Pole Station in Antarctica and (2) the Greenland West Coast Chain and two magnetically conjugate chains in Antarctica, AAL-PIP and BAS LPM. From 1 to 3 different isolated MPEs localized in corrected geomagnetic latitude were observed during 3 pre-midnight events; many were simultaneous within $3 \mathrm{~min}$ in both hemispheres. Their conjugate latitudinal amplitude profiles, however, matched qualitatively at best. During an extended post-midnight interval, which we associate with an interval of omega bands, multiple highly localized MPEs occurred independently in time at each station in both hemispheres. These nighttime MPEs occurred under a wide range of geomagnetic conditions, but common to each was a negative IMF Bz that exhibited at least 
a modest increase at or near the time of the event. A comparison of perturbation amplitudes to modeled ionospheric conductances in conjugate hemispheres clearly favored a current generator model over a voltage generator model for 3 of the 4 events; neither model provided a good fit for the pre-midnight event that occurred near vernal equinox.

\section{Introduction}

The study of Earth's space environment has in recent years become increasingly recognized as having significant practical importance because of the damaging impacts that disturbances in the magnetosphere and ionosphere can impose on technological infrastructure. Extreme geomagnetically-induced currents (GICs) can disrupt the operation of large-scale ground-based electrically conducting systems such as electrical power grids, pipelines, telecommunication cables, and railway systems (Ngwira and Pulkkinen, 2019). Given this practical emphasis, it is not surprising that nearly all studies of the high latitude magnetic and electrical perturbations that can generate (GICs) have been based on data from the northern hemisphere. It is becoming increasingly clear that the chain of physical processes in the near-Earth magnetosphere and ionosphere that can generate GICs is complex

(Viljanen, 1997; Henderson et al., 1998; Apatenkov et al., 2004; Ngwira et al., 2015, 2018; Kozyreva et al., 2018; and Dimmock et al., 2019), but large, impulsive magnetic perturbations have been linked both theoretically and observationally to the occurrence of large $|\mathrm{dB} / \mathrm{dt}|$ impulses that appear in ground-based magnetometer data (e.g., Viljanen, 1997; Viljanen et al., 2006).

Although several studies of GICs have noted their occurrence during substorms, it has become clear that the impulsive nighttime magnetic perturbation events that are temporally related to GICs are distinct from substorm onsets. The criterion for identifying a substorm onset to be included in the SuperMAG substorm lists (Newell and Gjerloev, 2011a,b) is a drop in SML (the SuperMAG version of the AL index) that was sharp (45 nT in $3 \mathrm{~min}$ ) and sustained (-100 nT average for 25 min starting 5 min after onset). In contrast to these stepfunction-like criteria, the large nighttime MPEs studied by Engebretson et al (2019a,b) and in this paper are unipolar or bipolar pulses of hundreds of $\mathrm{nT}$ and $~ 5-10$ min periods.

However, MPEs are still likely to be causally related to active conditions in the magnetotail such as bursty bulk flows and/or dipolarizing flux bundles (Angelopoulos et al., 1992; Sergeev et al., 1999; Kauristie et al., 2000; Zesta et al., 2000, 2006; Lyons et al., 2012; Gabrielse et al., 2014; Liu et al., 2014; and Engebretson et al., 2019b) that are expected to impact high latitude regions in both the northern and southern hemispheres. 
Although the technological risk from GICs is greater during magnetic storms, when the auroral oval expands to subauroral latitudes, impulsive magnetic perturbation events (MPEs) with duration 5 to 15 min have also been found to more often occur during nonstorm times (Viljanen et al., 2006) and at up to at least $78^{\circ}$ magnetic latitude (Engebretson et al., 2019a). A recent case study of three large amplitude MPEs observed using an extensive two-dimensional set of ground magnetometer arrays in Arctic Canada, Western Greenland, and Antarctica (Engebretson et al., 2019b) showed that these events appeared roughly simultaneously at near-magnetically-conjugate locations (at the northern and southern ends of the same magnetic field lines) in each hemisphere. In this study we present multi-station data from a large two-dimensional set of ground-based magnetometers in the northern hemisphere and magnetometers at magnetically conjugate locations in Antarctica, both covering a range in corrected geomagnetic (CGM) latitude from $\sim 65^{\circ}$ to over $80^{\circ}$. By detailing the similarities and differences between large MPEs in both hemispheres we provide additional information that may be helpful for understanding the physical mechanisms involved in their generation.

\section{Data Set and Event Identification Technique}

Vector magnetometer data used in this study were recorded by the MACCS (Engebretson et al., 1995) and CANMOS (Nikitina et al., 2016) arrays in Arctic Canada, the Greenland West Coast chain (https://www.space.dtu.dk/MagneticGroundStations), the conjugate AAL-PIP chain in Antarctica (Clauer et al., 2014), the British Antarctic Survey (BAS) Low Power Magnetometer chain (Kadokura et al., 2008), and the fluxgate magnetometer at South Pole Station, Antarctica (Lanzerotti et al., 1990; Engebretson et al., 1997). Data are presented in local magnetic coordinates. In the northern hemisphere (at MACCS, CANMOS and Greenland West Coastal chain stations) and in the southern hemisphere (at AAL-PIP and BAS LPM stations) the sensor axes are oriented as follows: X: magnetic north, Y: magnetic east, and Z: vertically down. The South Pole magnetometer sensors are X: magnetic north, Y: magnetic east, and Z: vertically upward (a left-handed system). The sampling rate of MACCS data is $2 \mathrm{~Hz}$, and for the other stations $1 \mathrm{~Hz}$.

Figure 1 and Table 1 show that South Pole Station in Antarctica is in approximate magnetic conjugacy to MACCS station Pangnirtung and CANMOS station Iqaluit in Canada. Figure 1 also shows that the six AAL-PIP stations in Antarctica, located about $20^{\circ}$ farther east in corrected geomagnetic (CGM) longitude, are in close magnetic conjugacy to the middle of the Greenland West Coast chain, and that the BAS LPM chain is conjugate in CGM magnetic latitude to several of the lower latitude Greenland West Coast stations, but 
approximately midway in CGM longitude between the Canadian and Greenland stations (Table 1).

The semi-automated procedure used to identify and quantify MPEs in these data sets is detailed in Engebretson et al. (2019a), and is summarized here. Routinely produced daily magnetograms (24-hour plots of magnetic fields in local geomagnetic coordinates) were displayed on a computer screen. Once a large-amplitude 5-10 minute duration magnetic perturbation was visually identified, the IDL cursor function was used to select times before and after a region of interest containing the MPE. The times and values of extrema in this interval were recorded for each component, and after application of a 10-point smoothing to reduce noise and eliminate isolated bad data points, the data were numerically differentiated. Plots of the time series of data and derivatives were produced and saved, and the maximum and minimum derivative values were automatically determined and recorded.

Auroral images obtained by DMSP spacecraft were used to confirm the presence of omega bands during the postmidnight interval. The DMSP Block 5D3 satellites F16-F19 were launched beginning in 2003 into circular polar orbits with altitudes $\sim 840 \mathrm{~km}$ and $1.7 \mathrm{~h}$ period. The Special Sensor Ultraviolet Spectrographic Imager (SSUSI) on each of these spacecraft consists of a scanning imaging spectrograph (SIS) whose field-of-view is scanned from horizon to horizon and a nadir-looking photometer system (NPS). The SIS scans are used to produce simultaneous monochromatic images at five UV 'colors' in the spectral range 115nm to 180nm (Paxton et al., 1993; Sotirelis et al., 2013). The images are scanned along the orbital track and thus do not provide an instantaneous picture. It takes about $30 \mathrm{~min}$ to complete a scan over the nightside auroral region like those shown in Figures 14 and 15.

\section{Event Studies}

In this section we present four intervals of large-amplitude MPEs that were observed at both northern and southern high latitudes. In each case we also show OMNI interplanetary magnetic field (IMF) and solar wind data, time-shifted to the nose of the magnetosphere, as well as the SYM/H index and the SuperMAG SML and SMU indices (Newell and Gjerloev, 2011a) of magnetic activity. The first three intervals occurred in the pre-midnight sector under conditions ranging from geomagnetically quiet to storm time. The fourth interval occurred in the post-midnight sector during the main and early recovery phases of a more intense magnetic storm.

For all three pre-midnight MPE intervals studied here, the largest $|\mathrm{dB} / \mathrm{dt}|$ values occurred during a sharp initial pulse which set up the MPE. In contrast, within the post- 
midnight interval sharp pulses were seen at different times at each site over a span of $\sim 1.5$ hours. Their multiple rapid variations resembled those of Pi 3 or Ps 6 pulsations (Opgenoorth et al., 1983; Solovyev et al., 1999; Apatenkov et al., 2020) rather than solitary impulses.

\subsection{Interval 1: 15 January $2018 \quad 00: 24-00: 51$ UT}

Figure 2a shows IMF and solar wind parameters from the OMNI database as well as the SuperMAG SML and SMU indices and the SYM/H index, from 2200 UT January 14, 2018 to 0200 UT January 15, 2018. Figures $2 \mathrm{~b}$ and 2c show 3-component magnetic field data from AAL-PIP PG3 in Antarctica and Qeqertarsuaq (GDH) in Greenland. These stations were in close magnetic conjugacy, separated by $0.6^{\circ}$ in CGM Lat and $1.1^{\circ}$ in CGM Lon (Table 1 and Figure 1). The shaded region, from 00:24 to 00:51 UT January 15, spans the large magnetic perturbation observed at both stations. Substorm onsets included in the SuperMAG substorm list for 2018 occurred at 23:32 UT January 14 at $67.8^{\circ}$ MLAT and 1.33 $\mathrm{h}$ MLT and 00:22 UT January 15 at $66.86^{\circ}$ MLAT and $1.77 \mathrm{~h} \mathrm{MLT).} \mathrm{The} \mathrm{times} \mathrm{of} \mathrm{these}$ onsets, marked in Figure 2a by red arrows, were $\sim 1$ hour and $\sim 2$ minutes, respectively, before the beginning of the MPE interval. The location of these substorm onsets, determined using data from all stations in the SuperMAG data base, was 4-5 h MLT distant from the MLTs of the arrays of stations analyzed for this event (Figure 3).

Before the onset of the MPE, the IMF magnitude increased slightly and the IMF Bz component was slightly negative but increasing toward 0. Both the IMF Bx and By components were near -4 nT (not shown), so the IMF had the most typical "garden-hose" orientation. The solar wind velocity (Vsw) and dynamic pressure (Psw) were modest and relatively steady. The SML index decreased rapidly from -62 to $-324 \mathrm{nT}$ at the time of the first substorm onset, decreased rapidly again from -139 to -883 nT beginning near the time of the second substorm onset, and increased toward -500 nT near the end of the MPE interval. The SYM/H index decreased slightly before MPE onset to $-14 \mathrm{nT}$ and also remained near this level during the MPE.

As shown in Figures $2 b$ and $2 c$, the Bx components at both GDH and PG3 reached their minimum value at 00:35 UT, 13 min after the most recent substorm onset. Perturbations in By and Bz had opposite signs at the two stations, and as was the case for each of the 4 events shown, also showed less similarity in shape than the Bx perturbations. The relative orientations of the $\mathrm{Bx}$ and By perturbations most likely reflect the hemispheric difference in the circular Hall current flow around a localized field-aligned current (FAC), counterclockwise in the northern hemisphere and clockwise in the southern hemisphere. Also shown 
in these figures are the magnitude of the maximum derivative in each component. Both the perturbations $(\Delta \mathrm{B})$ and derivative amplitudes $|\mathrm{dB} / \mathrm{dt}|$ in each component were slightly larger in the northern hemisphere.

Figure 3 shows Bx (north-south) component data from several stations during this event, organized by increasing local time (left to right) and decreasing magnetic latitude (top to bottom), and the second column of Table 2 shows the maximum $|\mathrm{dB} / \mathrm{dt}|$ values for each component for each of the stations shown in Figure 3. During this interval the largest derivative was in the $\mathrm{X}$ component at 8 stations, in the $\mathrm{Z}$ component at 5 stations, and in the Y component at none. Figure 3 a shows data from the near-conjugate South Pole and Pangnirtung station pair, Figure $3 b$ shows data from AAL-PIP stations PG2, PG3, and PG5 and BAS LPM stations M79 and M78 in Antarctica, and Figure 3c shows data from West Greenland stations UMQ, GDH, STF, GHB, FHB, and NAQ. The same vertical and horizontal ranges are used in each panel. At each station, the time of maximum $|\Delta \mathrm{Bx}|$ perturbations is shown.

There was good agreement in the timing of Bx minima near 00:35 UT between northern and southern hemisphere stations with $|\mathrm{MLAT}| \geq 73.9^{\circ}$ in both local time sectors: PGG, UMQ, and GDH in Canada and Greenland, and SP, PG2, and PG3 in Antarctica, but Table 2 shows that the $|\Delta \mathrm{Bx}|$ perturbations were larger in the northern (winter) hemisphere. However, the MLT dependence was complex: Figure 3a shows that farther west, the $\Delta \mathrm{Bx}$ value at SPA was smaller than that at PGG, but Table 2 indicates its peak derivative value was larger than that of any other station in the data set. Two minima in Bx occurred at three intermediate latitude stations (STF, PG5, and GHB) between 00:20 and 01:00 UT, with no simultaneity between stations, and none showed evidence of the minimum at 00:35 UT that was observed at more poleward stations. One maximum in Bx occurred at the four lowest latitude stations (FHB, M79, NAQ, and M78).

The $\Delta \mathrm{Bx}$ polarity reversal between $69.3^{\circ}$ and $66.6^{\circ}$ MLAT suggests the presence of an ionospheric flow shear, with westward flow poleward and eastward equatorward of it. The positive perturbation observed at the lower latitudes may represent the equivalent return current of the westward current in the negative $\Delta \mathrm{Bx}$ spike observed at higher latitudes. It is possible that the negative spike at 00:21 UT observed at PG5 was caused by a westward traveling surge that moved westward and poleward to appear successively later at more poleward stations: at 00:26 UT at STF, at 00:33 UT at Pangnirtung, and between 00:35 and 00:39 at PG3, PG2, GDH, and UMQ. This would be qualitatively consistent with the progressive appearance of MPEs at more westward and poleward stations found in three 
recent case studies of MPEs by Engebretson et al. (2019b) using a two-dimensional array of stations in Arctic Canada.

Figure $4 \mathrm{a}$ shows the north-south perturbation amplitudes $(\Delta \mathrm{Bx})$ and Figure $4 \mathrm{~b}$ shows the maximum derivative amplitude in any component observed at every available station during this event in the West Greenland Coastal Array (red triangles) and the conjugate AALPIP and BAS LPM arrays (blue asterisks). Discussion of Figure $4 \mathrm{c}$ and $4 \mathrm{~d}$ is deferred until section 4. In the MLAT range from $\sim 70^{\circ}$ to $\sim 76^{\circ}$, corresponding to a distance of $\sim 700 \mathrm{~km}$ in both hemispheres, the amplitudes of both the perturbations and derivatives were larger in the northern hemisphere. However, the latitude profiles for $\Delta \mathrm{Bx}$ and maximum $\mathrm{dB} / \mathrm{dt}$ in Greenland did not follow each other closely in the region of largest amplitudes. In both hemispheres the equatorward falloff of amplitude with MLAT was more gradual than its poleward counterpart.

\subsection{Interval 2: 16 March $2016 \quad 00: 34-00: 57$ UT}

This complex MPE interval, which had significant amplitude over an MLAT range of at least $10^{\circ}$, occurred during the early recovery phase of a weak magnetic storm, as shown in Figure 5a. The SYM/H index decreased modestly from -30 to -50 nT between 22:00 and 24:00 UT on March 15, and showed a slight $<5 \mathrm{nT}$ increase before the interval and a similar small decrease during the interval. The IMF magnitude remained steady near $8 \mathrm{nT}$ for $\sim 2 \mathrm{~h}$ before and during the highlighted interval and again the IMF Bz component was negative (-4 nT) but increased shortly before and during the interval. Both the IMF Bx and By components were near $0 \mathrm{nT}$ (not shown). Vsw and Psw were again relatively constant before and during the interval. A substorm onset occurred at 23:51 UT March 15, at 70.98 ${ }^{\circ}$ MLAT and $8.37 \mathrm{~h}$ MLT. The time of this onset, shown in Figure 5a, was 40 minutes before the beginning of the MPE interval, and it occurred more than $10 \mathrm{~h}$ MLT away from the magnetometer stations shown in Figure 6.

A broad minimum in SML and maximum in SMU were evident during this MPE interval, after which time both indices gradually returned to more quiet levels. The SML index dropped gradually from -284 nT at onset to a minimum of -742 nT at 00:18 UT, and at 00:43 UT exhibited a short -200 nT negative spike, near the time of the large amplitude spikes shown in Figures $5 \mathrm{~b}$ and $5 \mathrm{c}$.

Three-component magnetic field data from PG4 and STF (Figures 5b and 5c) show similar Bx waveforms with minima simultaneous to within 1 min, again oppositely directed 
perturbations in $\mathrm{By}$, and complex variations in Bx. In all three components the amplitudes of both the perturbations and derivatives were larger in the southern hemisphere.

This interval also showed latitude-dependent variations in timing that were very similar in both hemispheres (Figure 6). A Bx minimum occurred simultaneously to within 1 min at 00:48 UT at the four most poleward stations in both hemispheres ((SPA, PG2, PG3, and GDH, all above $73.9^{\circ} \mid$ MLAT|), but occurred earlier (at 00:42 UT) at the two Canadian stations (PGG, IQA). In the $|\mathrm{MLAT}|$ range from $69.8^{\circ}$ to $71.9^{\circ}$ a $\mathrm{Bx}$ minimum occurred nearly simultaneously at 00:37 UT at Antarctic stations PG4, M85 (not shown), and at STF in Greenland, and Bx minima appeared at PG5 in Antarctica and at SKT and GHB in Greenland 2-6 minutes later. A more temporally extended substorm bay in Bx rather than a single dominant but short-lived negative perturbation was observed at the four lower latitude stations (M81, M79, FHB, and NAQ). Rapid negative excursions in Bx were also evident at each of these four stations and at GHB, during the downward slope of the bay between 00:35 and 00:37 UT (just prior to the vertical dashed lines in Figure 6a and 6b), but were in each case (except at M79) relatively small. It is possible that the 00:35-00:37 UT disturbance that first appeared at these lower latitude stations expanded poleward and westward to appear later at higher latitude stations, as in interval 1.

Figure 7 shows latitudinal profiles of the $\Delta \mathrm{Bx}$ perturbation amplitude (panel a) and the maximum derivative amplitude (panel b), as in Figure 4. At all latitudes both quantities were consistently larger in the southern hemisphere, and the latitudinal profiles were similar, with one major exception: the derivative amplitude at M84, located $10^{\circ}$ magnetic longitude west of PG5 and other AAL-PIP stations, was substantially larger $(25.7 \mathrm{nT} / \mathrm{s})$ than the amplitude at PG5 (16.2 nT/s). Figure 6a shows that the $\triangle \mathrm{Bx}$ value at SPA in Antarctica was also larger than at the Arctic stations PGG and IQA.

The third column of Table 2 shows the maximum $|\mathrm{dB} / \mathrm{dt}|$ values for each component for each of the stations shown in Figure 6. During this interval the derivatives were consistently larger at all stations in the southern hemisphere than at northern hemisphere stations at comparable latitudes and local times. The largest derivative was in the $\mathrm{X}$ component at 10 stations, in the $\mathrm{Z}$ component at 3 stations, and in the $\mathrm{Y}$ component at one (SPA). Derivative magnitudes were nearly equal in $\mathrm{X}$ and $\mathrm{Z}$ at 2 stations.

\subsection{Interval 3: 8 May 2016 21:02-21:30 UT}

This MPE interval, which occurred shortly before the second minimum of a doubleminimum geomagnetic storm (minimum SYM/H -87 nT, Figure 8a), included an extremely 
large $\mathrm{dB} / \mathrm{dt}$ value of $37.7 \mathrm{nT} / \mathrm{s}$ at BAS LPM M79, but appeared only within an |MLAT| range of $\sim 5^{\circ}$, from $64^{\circ}$ to $69^{\circ}$. During and before this interval the IMF magnitude was relatively steady near $8 \mathrm{nT}$, and the IMF Bz component was increasing from a slightly negative value. The IMF Bx and By components were near +3 and $-3 \mathrm{nT}$, respectively (not shown), so the IMF had an "ortho-garden hose" orientation. Vsw was over $600 \mathrm{~km} / \mathrm{s}$ and falling slightly during the interval, and Psw was near $3.4 \mathrm{nPa}$. Multiple substorm onsets occurred at 1809 UT at $66.70^{\circ}$ MLAT and 2.75 $\mathrm{h}$ MLT; 18:48 UT at 70.6 MLAT and 7.13 $\mathrm{h}$ MLT; 19:08 UT at $65.94^{\circ}$ MLAT and 6.01 $\mathrm{h}$ MLT; 19:48 UT at 65.94 MLAT and 6.69 $\mathrm{h}$ MLT; and 20:12 UT at $65.94^{\circ}$ MLAT and $7.09 \mathrm{~h}$ MLT. The times of these onsets, shown in Figure 8a, were from $\sim 1$ - 3 hours before the beginning of the MPE interval, and they occurred $\sim 7$ to $12 \mathrm{~h}$ MLT away from the magnetometer stations shown in Figure 9.

The SML index decreased from $-457 \mathrm{nT}$ at the time of the latest substorm onset 20:12 UT) to $-1022 \mathrm{nT}$ at 20:23 UT, and returned to near $-500 \mathrm{nT}$ at 20:55 before dropping to -699 nT near the beginning of the MPE interval. The SMU index was relatively steady near 400 nT for nearly 3 hours, from 18:00 to 20:55 UT, before rising to $616 \mathrm{nT}$ at 21:02 UT, the beginning of the MPE interval. The variation of SMU and SML approximately in tandem shortly before and during the interval suggests the occurrence of a magnetospheric convection event or pseudobreakup. Both SML and SMU values gradually returned to more quiet levels during and after the MPE interval.

Figures $8 \mathrm{~b}$ and 8c show magnetograms from BAS LPM M79 and FHB, respectively, from 20:00 to 22:00 UT on this day. A single Bx minimum at M79 appeared at 21:07 UT, and two Bx minima appeared at FHB at 21:04 and 21:22 UT, respectively. The largest $\mathrm{dBx} / \mathrm{dt}$ excursion at FHB was substantial ( $-6.7 \mathrm{nT} / \mathrm{s})$, but was a factor of $\sim 5$ smaller than that at M79.

Figure 9 shows Bx component data from the four lowest latitude stations available in each hemisphere from 20:00 to 22:00 UT. Both $\Delta \mathrm{Bx}$ and the derivatives in each component at the Antarctic stations (Figure 9a) were highly localized in MLAT: as shown in Table 3, the maximum $|\mathrm{dBx} / \mathrm{dt}|$ value decreased to less than half its value at $\mathrm{M} 79$ within $1^{\circ}$ and $1.7^{\circ}$ toward higher and lower MLAT (at M81 and M78, respectively). The first MPE observed in Greenland occurred within $\sim 3$ minutes of the much larger MPE observed in Antarctica, and conversely there was no evidence of the second Greenland MPE at any of the Antarctic stations. Thus for both MPEs there was an apparent lack of conjugacy. However, as will be discussed in section 5, at least some of this lack of conjugacy might be attributed to longitudinal localization of both MPEs: BAS LPM stations M79 and M81 were located $~ 9^{\circ}$ 
in magnetic longitude west of the conjugate point of FHB - at distances of 431 and $429 \mathrm{~km}$, respectively. Figures 10a,b show that magnetometer deflections and derivative amplitudes at stations at $|\mathrm{MLAT}|>70^{\circ}$ in both hemispheres were at near background levels.

The fourth column of Table 2 shows the maximum $|\mathrm{dB} / \mathrm{dt}|$ values for each component for the lowest latitude stations shown in Figure 9. During this interval the derivatives were again consistently larger in the southern hemisphere than at northern hemisphere stations at comparable latitudes. The largest derivative was in the $\mathrm{X}$ component at all stations shown except FHB, where it was largest in the $\mathrm{Z}$ component.

The observations at BAS LPMs M81, M79, and M78, located in nearly a straight line with similar MLON (to within $1.5^{\circ}$ ) and MLAT (to within $2.7^{\circ}$ ), can provide additional information about this MPE. The distance from M79 to M81 is $139 \mathrm{~km}$, and from M79 to M78 is $240 \mathrm{~km}$. At the most equatorward station, M78, the minimum in Bx occurred at 2105 UT. At M79 it occurred at 2107 UT, and at M81 it occurred at 2108 UT. This indicates a possible drift of the epicenter of the MPE westward and poleward. This drift is again consistent with that found in the Engebretson et al. (2019b) case studies.

\subsection{Interval 4: 13 May 2015 05:30-08:00 UT}

This extended post-midnight interval occurred during the main phase of a large magnetic storm (minimum SYM/H = -95 nT), as shown in Figure 11a. The IMF magnitude was near $15 \mathrm{nT}$ before the beginning of the interval, and fell slightly to $12 \mathrm{nT}$ at its end, and the IMF Bz component rose unsteadily from a large negative value (-13 nT) at $0500 \mathrm{UT}$ to +4 nT by 07:00 UT. The IMF Bx and By components were near +10 and $-7 \mathrm{nT}$, respectively (not shown), so the IMF again had an "ortho-garden hose" orientation. Vsw fluctuated slightly near $600 \mathrm{~km} / \mathrm{s}$ during the event, and Psw varied near $7 \mathrm{nPa}$. Two substorm onsets occurred prior to this event, at 05:04 UT at $60.49^{\circ}$ MLAT and 1.87 $\mathrm{h}$ MLT and at 05:25 UT at $67.47^{\circ}$ MLAT and $21.15 \mathrm{~h}$ MLT. The times of these onsets were $26 \mathrm{~min}$ and $5 \mathrm{~min}$, respectively, before the beginning of the shaded MPE interval, and they occurred $\sim 1-2$ and 6$7 \mathrm{~h}$ MLT away from the magnetometer stations shown in Figure 12, respectively.

The SMU index rose gradually beginning near 04:35 UT from $\sim 250 \mathrm{nT}$ to a maximum of $507 \mathrm{nT}$ at 05:14 UT, fell to $\sim 300 \mathrm{nT}$ by 05:40 UT, and exhibited only modest variations during the remainder of the MPE interval. The SML index also began a gradual drop near 04:35 UT, but declined sharply from the time of the second substorm onset, 
reaching a minimum of $-1160 \mathrm{nT}$ at 05:46 UT before gradually returning toward more quiet levels, reaching values near -300 nT near 08:00 UT.

The beginning and end times of this interval (05:30 to 08:00 UT) correspond to the duration of double-minimum negative bays in the Bx component at M81 (Figure 11b) and FHB (Figure 11c). These bays showed a rapid recovery in the Bx component between 06:30 and 07:00 UT, followed by a slower recovery from 07:00 to 08:00 UT that was still characterized by large fluctuations in all 3 components. There was again little correspondence in the By and Bz components between the two stations.

Figure 12 shows that a large negative bay appeared all 14 stations shown, covering an MLAT range of $>10^{\circ}$, but was deeper and more extended at lower latitudes and in the southern hemisphere. This bay, and the many rapid perturbations embedded within it, resembles published signatures of omega band structures (e. g., Figure 4 of Opgenoorth et al., 1983). These multiple short-lived perturbations, which have been designated variously as Ps6 and Pi3 magnetic pulsations (Solovyev et al., 1999), appeared in all 3 components at all stations (not shown), and were often largest in the By component, but were highly localized. At each station, the maximum derivative amplitude in each component is again listed in Table 2. Derivative amplitudes generally increased from higher to lower MLAT, but the largest derivatives appeared at different times at each station, and spanned the time range from 05:50 to 07:40 UT. Only at one neighboring station pair (FHB and GHB, separated by $262 \mathrm{~km}$ ) at 06:55:11 and 06:55:08 UT, respectively, were nearly simultaneous large perturbations observed. The blue arrows in each panel show the times of the largest derivatives in the Bx component. Two > $6 \mathrm{nT} / \mathrm{s}$ derivatives in Bx appeared at M83 and M81 (Figure 12b), and two $>8 \mathrm{nT} / \mathrm{s}$ derivatives in Bx appeared at NAQ (Figure 12c). At all other stations Bx derivative amplitudes were $<6 \mathrm{nT} / \mathrm{s}$; for these only the largest Bx derivative is shown ( 2 of equal magnitude at SPA and FHB).

Figure 13a shows that similar latitudinal profiles of $\Delta \mathrm{Bx}$ occurred in both northern and southern hemispheres, with elevated values extending over nearly $15^{\circ}$ MLAT and generally larger at lower latitudes, but their amplitude was $20 \%$ to $60 \%$ larger in the southern (winter) hemisphere. The derivative amplitudes (Figure 13b) were again larger at lower latitudes. They were again somewhat larger in the southern hemisphere, but showed large differences between two pairs of Antarctic stations at similar MLAT but different MLON: M83 - M84 and PG4 - M85.

The fifth column of Table 2 shows the maximum $|\mathrm{dB} / \mathrm{dt}|$ values for each component for the stations shown in Figure 12. In contrast to the pre-midnight MPEs, the largest 
derivative was in the $\mathrm{X}$ component at 5 stations, in the $\mathrm{Y}$ component at 5 stations, in the $\mathrm{Z}$ component at 4 stations, and equal in the $\mathrm{Y}$ and $\mathrm{Z}$ components at 1 station.

\section{Comparison of amplitudes in conjugate hemispheres}

In each of the 4 MPE intervals studied, the latitudinal profiles in conjugate

hemispheres showed fair to good qualitative agreement (Figures 4, 7, 10, and 13). Conditions were dark at most sites in both hemispheres. During intervals 1, 3, and 4 both perturbation and derivative amplitudes were larger in the winter hemisphere by up to a factor of 3 , but during the second (near-equinox) event, Antarctic stations recorded consistently larger amplitudes. Derivative amplitudes (but not perturbation amplitudes) also varied significantly between stations in the southern hemisphere that differed in magnetic longitude by $6^{\circ}$ or more (e.g., the M84 - PG5 pair in Figure 7 and the M83 - M84 and PG4 - M85 pairs in Figure 13). Many studies have suggested that MPEs are driven by localized field-aligned currents (e.g., Viljanen et al., 2001; Viljanen and Tanskanen, 2011; Belakhovsky et al., 2019), and in models of magnetosphere - ionosphere electrodynamic drivers it is physically intuitive to use a circuit analogy and distinguish between generators which deliver a fixed current and those in which the voltage is fixed (Lysak, 1990).

Distinctions between the applicability of these two drivers can be revealed by analyzing the dependence of the ground magnetic response on the ionospheric conductance. If the magnetospheric driving of a FAC behaves as a voltage generator, then one expects the ground magnetic field perturbation to increase as the ionospheric conductance increases. In contrast, if the magnetospheric process behaves as a current generator, one expects the intensity of magnetic field perturbations to remain only weakly sensitive to the ionospheric conductance.

Quantitative relationships between conjugate $\Delta \mathrm{B}$ amplitudes and height-integrated ionospheric conductances for these two generators were examined by Pilipenko et al. (2019) using a simple "plasma box" model of the magnetosphere with asymmetric conjugate ionospheres driven by an external current located at the magnetospheric equatorial plane. The ranges of validity of current and voltage generators are determined by the ratio between an internal generator resistance and a load resistance. For a FAC generator, the local ionospheric resistance above an observation site plays the role of a load resistance, whereas the magnetospheric Alfvén wave resistance and the resistance of the conjugate ionosphere play the role of an internal source resistance. Oscillatory FACs interact with the ionosphere 
in a different way depending on relationship between the driver periodicity $\tau$ and the Alfven field line eigenperiod $\mathrm{T}_{\mathrm{A}}$.

For a forced quasi-DC driving $\left(\tau>>\mathrm{T}_{\mathrm{A}}\right)$,

$$
\frac{\Delta B_{\chi}^{(N)}}{\Delta B_{\chi}^{(S)}}=\frac{\Sigma_{H}^{(N)}}{\Sigma_{H}^{(S)}},
$$

and for excitation of resonant field line oscillations $\left(\tau \sim \mathrm{T}_{\mathrm{A}}\right)$,

$$
\frac{\Delta B_{\chi}^{(N)}}{\Delta B_{\chi}^{(S)}}=\frac{\Sigma_{H}^{(N)}}{\Sigma_{H}^{(S)}} \frac{\Sigma_{P}^{(S)}}{\Sigma_{P}^{(N)}} .
$$

The quasi-DC driving of a FAC corresponds to a voltage generator, for which the ground magnetic response is proportional to the ionospheric Hall conductance. The excitation of resonant field line oscillations corresponds to a current generator, for which the ground magnetic response only weakly depends on the ionospheric conductance.

In order to determine the applicability of either of these models, the ratio of conductances at conjugate points can be compared with the ratio of magnetic disturbance amplitudes. Because MPEs are localized in both latitude and longitude, it is best to focus on stations observing the maximal amplitude of the MPE as well as to examine these ratios at more than one station. The bottom panels of Figures 4, 7, 10, and 13 show the ionospheric conductances calculated for each interval at all available West Greenland and conjugate AAL-PIP and BAS-LPM stations. Solid lines and dashed lines in panel c) of these figures denote Pedersen conductances $\left(\Sigma_{P}\right)$ and Hall conductances $\left(\Sigma_{H}\right)$, respectively. These were determined using an updated AMIE procedure based an empirical model parameterized by solar zenith angle and the solar radio flux index, $F 10.7$ (Cousins et al. (2015).

Cousins et al. (2015) also noted that on physical grounds one would expect auroral precipitation to contribute to ionospheric conductances. Panel d) of Figures 4, 7, and 13 shows the above conductances plus conductances determined using the empirical relationship of Robinson et al (1987) that relates particle flux and energy output to conductance, using the OVATION Prime empirical auroral precipitation model (Newell et al., 2009, 2010, 2014). The OVATION Prime model is parameterized by solar wind driving, developed using energetic particle measurements from the low-orbiting Defense Meteorological Satellite Program (DMSP) satellites. Distinguishing features of the model include an optimized solar windmagnetosphere coupling function which predicts auroral power significantly better than any interplanetary parameter or geomagnetic index. The model separates aurora into categories, 
and provides separate parameter fits for different $\Phi /$ MLT bins, thus permitting each type of aurora and each location to have different responses to season and solar wind input. This augmented model contributed only negligible additional conductances for interval 3 because the modeled auroral zone was located at lower latitudes than the MLAT range of the available stations, so Figure 10 does not include this additional panel.

However, Cousins et al. (2015) noted that large uncertainties remain in all current conductance models. They evaluated a number of conductance models and adjustments, including both of those described above, using metrics based on comparing SuperDARN plasma drift data to AMPERE field-aligned current data by means of these conductance models, and found that none of the model combinations they tested generated significantly better agreement. In addition, the localized field-aligned currents that drive MPEs are expected to produce localized increases of unknown size in ionospheric conductances, and no model including such effects yet exists.

During the northern winter event shown in Figure 4, the magnetic perturbations and derivatives were mostly somewhat larger in the northern hemisphere, but in both conductance models both $\Sigma_{P}$ and $\Sigma_{H}$ were larger in the southern hemisphere. These relations are opposite to those expected for a voltage generator. Southern hemisphere (summer) conductances based on the AMIE model (Figure 4c) increased relatively smoothly with MLAT, while in the augmented model (Figure 4d) the contribution of modeled auroral precipitation is evident for MLAT $<70^{\circ}$. Northern hemisphere (winter) conductances based on the AMIE model were nearly constant, and the auroral contribution in the augmented model extended to $73^{\circ}$ MLAT. These additions are consistent with the center of the modeled auroral zone being located at or equatorward of $65^{\circ}$ MLAT.

Inverse interhemispheric patterns are evident in Figure 13cd during northern summer events: magnetic perturbations and derivatives were mostly larger in the southern hemisphere, and conductances were much larger in the northern hemisphere. Northern hemisphere (summer) conductances based on the AMIE model (Figure 13c) increased relatively smoothly with MLT, while southern hemisphere conductances were nearly constant. The augmented model (Figure 13d) again increased the conductances at lower latitudes, but in this case again more rapidly in the southern hemisphere. The MPE event in interval 3 (Figure 10) was considerably more localized in latitude, and also occurred in a region with nearly constant conductances that was poleward of the modeled auroral zone. Both intervals 3 and 4 occurred during northern summer and showed the same seasonal 
interhemispheric patterns. It is also clear in Figures 4, 10, and 13 that peak MPE amplitudes occurred in latitudinal regions of near-constant conductances, based on both models. These relations indicate that for both pre-midnight and post-midnight events during solstice conditions the voltage generator model is not applicable to MPEs.

In order to make a more quantitative comparison between models, we chose 4 station pairs in regions of relatively constant conductances (variations of $<1 \mathrm{~S}$ ) from both interval 1 (between $69^{\circ}$ and $76^{\circ}$ MLAT) and interval 4 (between $70^{\circ}$ and $76^{\circ}$ MLAT) and calculated both $\triangle \mathrm{Bx}$ ratios and the AMIE model conductance ratios defined in equations (1) and (2). The ratios between left and right sides of equation (1) for a voltage generator model were $7.08 \pm 3.96$ and $0.159 \pm 0.032$ for intervals 1 and 4 , respectively (nearly inverse between winter and summer), while the corresponding ratios of equation (2) for a current generator model were $1.48 \pm 0.15$ and $1.10 \pm 0.17$, both much closer to unity, and thus approximately satisfying the equality.

Although equations (1) and (2) were derived to compare only the amplitudes of perturbations in $\mathrm{B}(\Delta \mathrm{B})$ in the northern and southern hemispheres, we also used them to compare the ratios of the derivatives in each hemisphere. That is, we used $|\mathrm{dBx} / \mathrm{dt}|$ ratios instead of $\Delta \mathrm{Bx}$ ratios on the left side of equations (1) and (2), and found similar results. The ratios between the left and right sides of the modified equation (1) for a voltage generator model were $6.16 \pm 3.42$ and $0.191 \pm 0.059$ for intervals 1 and 4 , respectively, and the ratios for the modified equation (2) for a current generator model were $1.31 \pm 0.15$ and $1.35 \pm$ 0.465 . The greater scatter in the $|\mathrm{dB} / \mathrm{dt}|$ ratios for both models using data from interval 4 is consistent with the greater variability in $|\mathrm{dB} / \mathrm{dt}|$ values for this interval shown in Figure $13 \mathrm{~b}$, which we attributed to longitudinal variations. Given the known uncertainties in the modeled conductances (Cousins et al., 2015), comparison of these ratios indicates the reasonableness of using a current generator model to drive these events.

The conductances for the 16 March 2016 pre-midnight event that occurred close to equinox (Figure 7c,d) showed more complex behavior. The AMIE conductances were below $1 \mathrm{~S}$ in both hemispheres below $72^{\circ}$ MLAT (Figure 7c), but the southern hemisphere conductances increased toward higher latitudes while the northern hemisphere conductances remained constant. The augmented conductances shown in Figure $7 \mathrm{~d}$ again showed the influence of an auroral zone for MLAT $<\sim 72^{\circ}$. As with the other intervals, neither conductance profile matched the large-scale latitudinal profiles of magnetic perturbations or derivatives shown in Figures $7 \mathrm{a}$ and $7 \mathrm{~b}$; the largest perturbations and derivatives occurred between $66^{\circ}$ and $72^{\circ}$ MLAT, in ranges of relatively flat conductances in the AMIE model 
and of both high and low conductances in the augmented model. During this event both perturbations and derivatives were larger in the southern hemisphere even near $72^{\circ}$ MLAT, where the conductances for both models were nearly equal. In addition, the latitudinal profile in the southern hemisphere between $69^{\circ}$ and $72^{\circ}$ MLAT (blue traces) showed sharp changes in conductances between M84 and PG5 and between PG4 and M85 (Figures 7c,d) that correspond to sharp changes in derivative and perturbation amplitude (Figures 7a,b). Similar sharp changes also appeared in Figure 10c. As noted near the beginning of this section, these changes appear to be linked to differences in station longitude, but the relative polarity of the changes is more consistent with a voltage generator model than a current generator model.

Several factors may complicate the modeling of ionospheric conductances in magnetically conjugate points, especially near equinoxes: a) the differing effects on ground conductivity of coastlines and oceans in the north vs. ice sheets in the south, b) the different distances and azimuths between the geographic and geomagnetic poles in opposite hemispheres (Liou et al., 2018), and c) the fact that Antarctic stations in this study were situated at $13-18^{\circ}$ higher geographic latitude than Arctic stations at similar MLAT. However, addressing these factors quantitatively is beyond the scope of this paper.

\section{Discussion}

This study has presented four intervals of nighttime MPEs observed by multiple magnetometers in near-magnetically conjugate regions in both polar regions. We here summarize both the commonalities and differences between these events, and also provide information confirming that interval 4 was associated with auroral omega bands.

The geomagnetic context of these four MPE intervals was similar only in that the Bz component of the IMF was < 0 before each event, and had at least a modest increase at or near the time of the event. MPEs could occur during both magnetically quiet times and storm times, but little or no change in solar wind pressure or velocity occurred shortly before or during each event, and there was no consistent pattern in IMF Bx or By levels or trends. Clear minima in the SML index were evident in each of the MPE intervals presented here, but as was the case for the statistical and event studies of MPEs presented by Engebretson et al. (2019a,b), there was no consistent timing of events relative to the most recent substorm onset(s).

The availability of data from latitudinally-spaced stations covering nearly $15^{\circ}$ in MLAT makes it possible to characterize the latitudinal extent of individual MPEs. Premidnight MPEs did not extend over large latitude ranges: one, two, or three independent 
events could appear across the available latitude range, with the more poleward events occurring some few minutes later. Simultaneous large-amplitude pre-midnight impulses in event 1 occurred over an MLAT range of $\sim 320 \mathrm{~km}$ (the distance from STF to GHB, the extent of the central range in Figure 3). In event 2 they occurred over ranges from $436 \mathrm{~km}$ (the distance from PG4 to M84, the central range in Figure 6 in which a large negative Bx impulse dominated the signal) to $703 \mathrm{~km}$ (the distance from PG4 to M79, the full range of latitudes over which a Bx minimum near 0037 UT was observed).

The amplitude and location data for the MPE event during interval 3 (Figure 10) can be used to estimate its latitudinal and longitudinal scale size. Using a linear slope calculation between pairs of stations gives the half-amplitude falloff distances shown in Table 3. For the two lowest-latitude and relatively closely-spaced BAS-LPM station pairs, these latitudinal distances ranged from 106 to $192 \mathrm{~km}$, and for the two somewhat less closely-spaced West Greenland stations at nearly the same magnetic longitude, $204 \mathrm{~km}$. The longitudinal halfamplitude falloff distances between BAS LPM stations M81 and M79 and the conjugate location to Greenland station FHB were 446 and 262 km, respectively. These latitudinal falloff distances are roughly comparable to but mostly lower than the $\sim 275 \mathrm{~km}$ twodimensional half-amplitude radius calculated for several events in Arctic Canada using the SECs technique by Engebretson et al. (2019a,b), and the longitudinal falloff distances are comparable to or somewhat higher. An MPE event with even larger differences in perturbation amplitude between relatively closely spaced stations than this one is shown in Figures 3 and 4 of Pulkkinen et al. (2015).

During the extended post-midnight interval multiple highly localized MPEs occurred independently in time at each station in both hemispheres, embedded within large amplitude, longer-duration magnetic bays (Figure 12), with only the exception of the near-simultaneous events at the FHB-GHB station pair noted above. MPE derivative amplitudes $\geq 6 \mathrm{nT} / \mathrm{s}$ appeared from $65.0^{\circ}$ to $71.9^{\circ}$ MLAT (NAQ to STF, a distance of $700 \mathrm{~km}$ ). Based on the latitudinal profiles in Figure 13, showing increasing perturbation and derivative amplitudes toward the lower MLAT end of the range of available stations, we consider it to be likely that these bays and their associated large MPEs may have extended even farther equatorward.

The pre- and post-midnight MPEs also differed in the directions of their largest perturbations. Pre-midnight MPEs were often largest in the Bx component, with some largest in Bz but with By largest at only one station (out of 37) in all 3 events. In contrast, postmidnight MPEs were often largest in the By component. This difference is consistent with earlier observations reported by Viljanen et al. (2001), who noted the strong southward 
direction of magnetic field fluctuations for large events in the auroral zone midnight sector, compared to a more East-West alignment in the morning sector.

Many of the nighttime MPEs in intervals 1 and 2 occurred simultaneously to within 12 minutes in latitudinal ranges of 300-700 km in conjugate hemispheres. The MPEs in interval 3 exhibited more significant differences between hemispheres, but these may have been caused by the greater longitudinal separation between available conjugate stations during this interval. Although it might be expected that magnetic perturbations in high latitude regions should show some symmetry (or at least some form of direct control of asymmetry by the orientation of the interplanetary magnetic field, season, or ionospheric conductivity), Kim et al. (2013) documented that this is seldom true for dayside magnetic impulse events (the high latitude geomagnetic response to sudden changes in solar wind pressure). They suggested that these asymmetric dayside ground responses might be of local origin rather than magnetospheric origin.

\subsection{Connection to omega bands and their physical mechanisms}

We noted in section 3.4 that the large-scale magnetic field structure and closelyspaced large magnetic perturbations in interval 4 resembled those associated with omega bands. This interval occurred in the morning sector during the recovery phase of a major substorm, when omega bands are often observed to occur.

Ground-based auroral images were first used to identify and characterize omega bands (e.g., by Akasofu and Kimball, 1964), and these were later supplemented by satelliteborne imagers (Akasofu, 1974). Although the THEMIS ASI Availability page http://themis.ssl.berkeley.edu/gmag/asi_list.php showed that the Narssarsuaq imager in Greenland was not operating on this day, three of the four operating DMSP spacecraft (F17, F18, and F19) provided coverage of the region of Antarctica where BAS LPM M81 and M83 were located during part of the time span of interval 4. Similar images over the northern (summer) hemisphere had little contrast because of contamination by sunlight.

Figure 14 shows a sequence of southern hemisphere passes of DMSP F17 between 0 and $~ 8$ UT on May 13, 2015. The time tag shown for each image is the UT time when the highest magnetic latitude pixel was imaged, which in every image is around the center of the crescent-shaped portion of the imaged auroral oval. The field of view of the auroral imager moved successively farther west with each successive orbit because of Earth's rotation relative to a fixed orbital plane. As was the case for the event studied by Apatenkov et al. 
(2020), these images show that omega bands along the morning sector auroral oval were evident both before and during the 05-08 UT interval of MPEs shown in Figures 11 and 12.

Figure 15 shows auroral images near 6 UT from DMSP F18 and F19, respectively. Both images show two south-north aligned transpolar auroral arcs surrounding the locations of BAS LPM M81 and M83 that connected to an east-west auroral arc at lower latitude. The latter arc again showed clear undulations in the form of omega bands.

The main magnetic signature of a series of eastward drifting omega bands (see e.g. Opgenoorth et al. 1983) is a wavy (pulsation-like) magnetogram, superimposed on a declining electrojet bay during the recovery phase of a previous substorm. The typical periodicity of "pulsations" in this wavetrain is of the order of 5-40 min. As Opgenoorth et al. (1983) have shown in more detail, Omega bands are caused by a sequence (or rather "train") of alternating upward and downward localized field- aligned currents (upward in the auroral tongue and downward in the auroral hole - the "inverted Omega") leading to a wavy undulation of the pre-existing westward substorm electrojet. As the negative magnetic Xcomponent of this electrojet is very large throughout the substorm recovery, the signature of omega bands in best seen in the magnetic $\mathrm{Y}$ and $\mathrm{Z}$ component, with a typical phase shift of $90^{\circ}$ between the $\mathrm{Y}$ and $\mathrm{Z}$ components. In the northern hemisphere a southward current $(+\mathrm{By}$ disturbance) into the hole is followed by a positive Bz-disturbance inside the inverted omegaband cavity. After this structure the By-component turns negative after the hole has passed (northward current undulation), again followed by a negative Bz-component deviation in the auroral tongue.

Figure 16 shows By and Bz component data from a) Greenland stations FHB and NAQ, which were close to the northern hemisphere auroral oval, and b) Antarctic stations M81 and M83, which were located respectively further poleward from the auroral oval, during an interval containing some of the largest amplitude perturbations, 0630-0700 UT. The approximate times of two maxima in By at each station are indicated by the vertical red bars, and the corresponding maxima in $\mathrm{Bz}$ are indicated by vertical blue bars. The $\mathrm{Bz}$ component lags the By component by $\sim 90^{\circ}$ at each station in both hemispheres. The uncertainty of the marked times is related to the presence of 1) smaller fluctuations near each station and 2) possibly larger fluctuations originating at somewhat greater distances. Note that there is a pulsation in the FHB By data centered near 0642:30 UT for which there is no corresponding pulsation in the NAQ data.

That these structures drift eastward is evident from the time delay of $\sim 3$ minutes between the maxima of the By (and Bz) components of both events from FHB to NAQ 
(Figure 16a), the latter being located $\sim 230 \mathrm{~km}$ east and $\sim 50 \mathrm{~km}$ equatorward. This delay is consistent with an eastward drift of $\sim 1.3 \mathrm{~km} / \mathrm{s}$. Opgenoorth et al (1983) reported drifts of several hundreds of $\mathrm{m} / \mathrm{s}$ for an ideal almost sinusoidal omega band case, but this MPE event is a very strong and active case so a somewhat higher velocity might be expected.

Little or no time delay of these maxima was evident between M81 and M83 (Figure 16b), consistent with their location considerably poleward of the omega bands along the main oval and at similar local times.

A recent paper by Apatenkov et al. (2020) also provided detailed observations of a very large GIC that was associated with an interval of omega bands. They modeled this event using the sum of two basic current systems: a 1D linear current (mimicking the auroral electrojet) and a 2D vortex that passed eastward over the field of view of the ground magnetometers. As a result of pointing out that the magnetic field created by ionospheric and magnetospheric currents may vary due to both temporal changes of current amplitudes and to the motion of the current structures, they suggested that propagating nonexplosive and relatively long-lived structures might be responsible for large rapid magnetic field variations observed on the ground if their propagation speeds were sufficiently large.

The magnetospheric source of these currents and rapid magnetic field variations may be, as Partamies et al. (2017) and Weygand et al. (2015) have suggested, fast earthward flows in the magnetotail, e.g., bursty bulk flows (BBFs, Angelopoulos et al., 1992) or the more localized dipolarizing flux bundles (DFBs) described by Liu et al. (2014). Palin et al. (2015) found that highly localized FACs and ionospheric currents were associated with BBFs and/or dipolarizing flux bundles observed by THEMIS spacecraft in the near magnetotail, and suggested that these might be the smallest elements of substorms and pseudobreakups. A recent satellite-ground study by Liu et al. (2018) also found that omega bands are related to a flow shear near the inner edge of the plasma sheet, and suggested that an enhanced flow in the magnetosphere drives the omega bands by triggering plasma instabilities. Within a BBF, the flow velocity exhibits peaks of very large amplitude with a characteristic time scale of the order of a minute, which are usually associated with magnetic field dipolarizations and ion temperature increases.

Although mid- or small-scale magnetotail flows are likely the ultimate sources for the field-aligned and ionospheric currents that generate nighttime MPEs, the contrast between the highly localized nature of the MPEs at each station observed during the post-midnight event and the larger-scale synchronicity of MPEs observed during the three pre-midnight events suggests that even smaller-scale magnetosphere-ionosphere coupling processes and resulting 
plasma instabilities may play a significant role in generating post-midnight MPEs. We note that Sato et al. (2017) similarly concluded their study of omega bands by strongly suggesting that magnetosphere-ionosphere coupling should play an important role in the formation of omega band auroras.

\section{Summary and Conclusions}

Under both quiet and moderately disturbed geomagnetic conditions large premidnight MPEs at high magnetic latitudes exhibited fair to good hemispheric conjugacy in the timing of the equatorward excursion of their $\mathrm{N}-\mathrm{S}$ component $(\Delta \mathrm{Bx})$ and fair conjugacy in their latitudinal profiles and amplitude peaks. During interval 3, which occurred during a highly disturbed interval, there was little similarity in MPE occurrence or amplitude between hemispheres, but the MPE appeared to be highly localized in both latitude and longitude, and available stations in opposite hemispheres were separated in longitude. Although the opposite orientation of the $\Delta \mathrm{By}$ perturbations in conjugate hemispheres was consistent with Hall currents surrounding localized FACs, the shapes of the perturbations in the By and Bz components were rarely similar in conjugate hemispheres.

The $\Delta \mathrm{Bx}$ amplitude was largest in the winter hemisphere during 3 of the 4 intervals presented here, and comparison of conjugate amplitudes and modeled ionospheric conductances suggested that the MPEs were fit much better by a current generator model than by a voltage generator model. However, during near-equinox interval 2 the $\Delta \mathrm{Bx}$ amplitudes were strongest in the southern hemisphere, and neither a simple current or voltage generator model was consistent with these amplitudes. In addition, a conductance model including auroral precipitation effects may suggest that the MPEs observed in this study occurred at or poleward of the poleward edge of the auroral zone, consistent with the multi-instrument MPE case studies of Engebretson et al. (2019b).

These large nighttime MPEs occurred under a range of solar wind and IMF conditions, but common to all four intervals was a negative IMF Bz that exhibited at least a modest increase at or near the time of the event.

Large $\mathrm{dB} / \mathrm{dt}$ values occurred both pre- and post-midnight. During the 3 pre-midnight intervals they were usually isolated and were largest in the $\mathrm{X}$ and $\mathrm{Z}$ components and smallest in $\mathrm{Y}$ at all but one station in one pre-midnight event. During the post-midnight interval they were grouped in quasi-periodic patterns embedded within a large magnetic bay, and the largest values could occur in any component. 
The local time range of the more clearly impulsive events matches that of BBFs and/or dipolarizing flux bundles, while we have shown evidence in both the DMSP images and the magnetic data that omega bands were connected to the largest magnetic deviations during the dawn sector interval. These results may indicate that two separate and highly localized magnetosphere-ionosphere coupling mechanisms may be responsible for generating the large, rapid geomagnetic perturbations that generate GICs.

\section{Acknowledgements}

We thank the reviewers for their helpful and detailed comments. This work was supported by National Science Foundation grants AGS-1651263 to Augsburg University, AGS-1654044 to the University of Michigan, OPP-1744828 to Virginia Tech, and OPP1643700 to the New Jersey Institute of Technology; and Natural Environmental Research Council grant NE/R016038/1 to the British Antarctic Survey. HO and AS thank the National Swedish Space Agency (SNSA) for support.

Solar wind and IMF data are available at the Goddard Space Flight Center Space Physics Data Facility at https://cdaweb.sci.gsfc.nasa.gov/index.html/, as are also data from the Greenland West Coast magnetometer chain. MACCS and CANMOS magnetometer data are available in IAGA 2002 ASCII format at http://space.augsburg.edu/maccs/requestdatafile.jsp and http://geomag.nrcan.gc.ca/datadonnee/sd-en.php, respectively. South Pole Station magnetometer data are available in ASCII format at https://antarcticgeospace.njit.edu/Data/. AAL-PIP magnetometer data are available in CDF and IDL save set formats at http://mist.nianet.org/ and in ASCII format at https://cdaweb.gsfc.nasa.gov. BAS LPM magnetometer data are available at https://data.bas.ac.uk/full-record.php?id=GB/NERC/BAS/AEDC/00263. DMSP SSUSI auroral imager data are available at https://ssusi.jhuapl.edu/gal_edr-aur_cs.

The SML and SMU indices are available at http://supermag.jhuapl.edu/indices/, and the SuperMAG substorm database is available at http://supermag.jhuapl.edu/substorms/ . Jesper Gjerloev is SuperMAG Principal Investigator. These SuperMAG products are derived from magnetometer data from INTERMAGNET, Alan Thomson; USGS, Jeffrey J. Love; CARISMA, PI Ian Mann; CANMOS, Geomagnetism Unit of the Geological Survey of Canada; The S-RAMP Database, PI K. Yumoto and Dr. K. Shiokawa; The SPIDR database; AARI, PI Oleg Troshichev; The MACCS program, PI M. Engebretson; GIMA; MEASURE, UCLA IGPP and Florida Institute of Technology; SAMBA, PI Eftyhia Zesta; 210 Chain, PI K. Yumoto; SAMNET, PI Farideh Honary; IMAGE, PI Liisa Juusola; Finnish 
Meteorological Institute, PI Liisa Juusola; Sodankylä Geophysical Observatory, PI Tero

Raita; UiT the Arctic University of Norway, Troms $\varnothing$ Geophysical Observatory, PI Magnar G.

Johnsen; GFZ German Research Centre For Geosciences, PI Jürgen Matzka; Institute of

Geophysics, Polish Academy of Sciences, PI Anne Neska and Jan Reda; Polar Geophysical

Institute, PI Alexander Yahnin and Yarolav Sakharov; Geological Survey of Sweden, PI

Gerhard Schwarz; Swedish Institute of Space Physics, PI Masatoshi Yamauchi; AUTUMN,

PI Martin Connors; DTU Space, PI Dr. Thom R. Edwards and Anna Willer; PENGUIn;

South Pole and McMurdo Magnetometer, PIs Louis J. Lanzerotti and Allan T. Weatherwax;

ICESTAR; RAPIDMAG; British Antarctic Survey; McMAC, PI Dr. Peter Chi; BGS, PI Dr.

Susan Macmillan; Pushkov Institute of Terrestrial Magnetism, Ionosphere and Radio Wave

Propagation (IZMIRAN);; MFGI, PI B. Heilig; Institute of Geophysics, Polish Academy of

Sciences, PI Anne Neska and Jan Reda; and University of L'Aquila, PI M. Vellante; BCMT,

V. Lesur and A. Chambodut; Data obtained in cooperation with Geoscience Australia, PI

Marina Costelloe; AALPIP, co-PIs Bob Clauer and Michael Hartinger; SuperMAG; Data obtained in cooperation with the Australian Bureau of Meteorology, PI Richard Marshall.

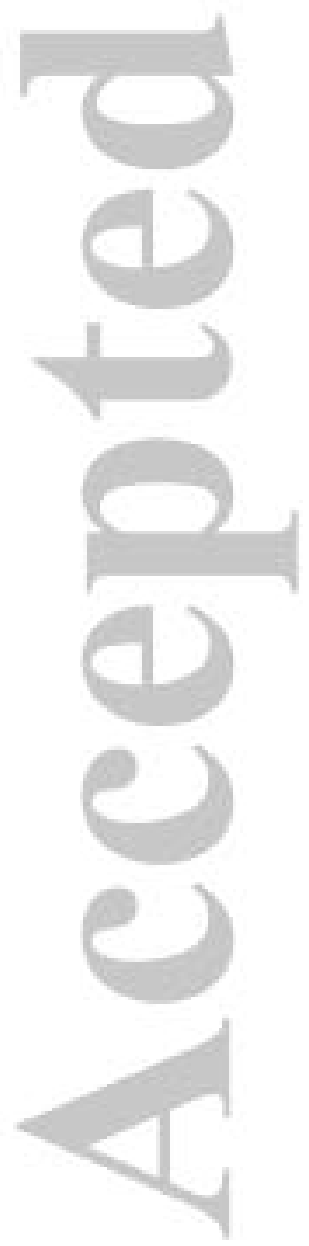




\section{References}

Akasofu, S.-I, and D. S. Kimball (1964), The dynamics of the aurora, 1, Instabilities of the aurora, Journal of Atmospheric and Terrestrial Physics, 26, 205-211,

doi:10.1016/0021-

9169(64)90147-3

Akasofu, S.-I. (1974), A study of auroral displays photographed from the DMSP-2 satellite and

from the Alaska meridian chain of stations, Space Science Reviews, 16, 617-725, ISSN:

0038-6308

André, D., and W. Baumjohann (1982), Joint two-dimensional observations of ground magnetic

and ionospheric electric fields associated with auroral currents. 5. Current system associated with eastward drifting omega bands, Journal of Geophysics, 50, 194-201, https://journal.geophysicsjournal.com/JofG/article/view/201.

Angelopoulos, V., W. Baumjohann, C. F. Kennel, F. V. Coroniti, M. G. Kivelson, R. Pellat, R. J.

Walker, H. Luehr, and G. Paschmann, (1992), Bursty bulk flows in the inner central plasma sheet. Journal of Geophysical Research, 97, 4027-4039, doi:10.1029/91JA02701

Apatenkov, S. V., V. A. Sergeev, R. Pirjola, and A. Viljanen (2004), Evaluation of the geometry

of ionospheric current systems related to rapid geomagnetic variations, Annales Geophysicae, 22, 63-72, doi:10.5194/angeo-22-63-2004

Apatenkov, S. V., Pilipenko, V. A., Gordeev, E. I., Viljanen, A., Juusola, L., Belakhovsky, V. B.,Sakharov, Ya. A., and Selivanov, V. N. (2020), Auroral omega bands are a significant

cause of large geomagnetically induced currents, Geophysical Research Letters, 47, e2019GL086677, doi:10.1029/2019GL086677

Belakhovsky, V., V. Pilipenko, M. Engebretson, Ya. Sakharov, and V. Selivanov (2019), Impulsive disturbances of the geomagnetic field as a cause of induced currents of electric

power lines, Journal of Space Weather and Space Climate, 9, A18, doi:10.1051/swsc/2019015 
Clauer, C. R., H. Kim, K. Deshpande, Z. Xu, D. Weimer, S. Musko, G. Crowley, C. Fish, R. Nealy, T. E. Humphreys, J. A. Bhatti, and A. J. Ridley (2014), An autonomous adaptive

low-power instrument platform (AAL-PIP) for remote high-latitude geospace data collection, Geosci. Instrum. Method. Data Syst., 3, 211-227, doi:10.5194/gi-3-211-

2014

Cousins, E. D. P., T. Matsuo, and A. D. Richmond (2015), Mapping high-latitude ionospheric electrodynamics with SuperDARN and AMPERE, J. Geophys. Res. Space Physics, 120

5854-5870, doi:10.1002/2014JA020463

Dimmock, A. P., L. Rosenqvist, J-O. Hall, A. Viljanen, E. Yordanova, I. Honkonen, M.

André, and E. C. Sjöberg (2019), The GIC and geomagnetic response over Fennoscandia to the

7-8 September 2017 geomagnetic storm, Space Weather, 17, 989-1010, https://doi.org/10.1029/2018SW002132

Engebretson, M. J., W. J. Hughes, J. L. Alford, E. Zesta, L. J. Cahill, Jr., R. L. Arnoldy, and $\mathrm{G}$.

D. Reeves (1995), Magnetometer array for cusp and cleft studies observations of the spatial extent of broadband ULF magnetic pulsations at cusp/cleft latitudes, Journal of Geophysical Research, 100, 19371-19386, doi:10.1029/95JA00768

Engebretson, M. J., Araki, T., Arnoldy, R. L., Carpenter, D. L., Doolittle, J. H., Fukunishi, H., et

al. (1997), The United States automatic geophysical observatory (AGO) program in Antarctica, in M. Lockwood, M. N. Wild, \& H. J. Opgenoorth (Eds.), the SatelliteGround Based Coordination Sourcebook, ESA-SP-1198 (pp. 65-99). ESTEC,

Noordwijk,

Netherlands: ESA Publications.

Engebretson, M. J., Pilipenko, V. A., Ahmed, L. Y., Posch, J. L., Steinmetz, E. S., Moldwin, M.

B., Connors, M. G., Weygand, J. M., Mann, I. R., Boteler, D. H., Russell, C. T., and Vorobev, A. V. (2019a), Nighttime magnetic perturbation events observed in Arctic Canada: 1. Survey and statistical analysis, Journal of Geophysical Research: Space Physics, 124, 7442-7458, doi:10.1029/2019JA026794

Engebretson, M. J., E. S. Steinmetz, J. L. Posch, V. A. Pilipenko, M. B. Moldwin, M. G. 
Connors, D. H. Boteler, I. R. Mann, M. D. Hartinger, J. M. Weygand, L. R. Lyons, Y. Nishimura, H. J. Singer, S. Ohtani, C. T. Russell, A. Fazakerley, and L. M. Kistler (2019b), Nighttime magnetic perturbation events observed in Arctic Canada: 2. Multiple-instrument observations, Journal of Geophysical Research: Space Physics, 124 ,

7459-7476, doi:10.1029/2019JA026797

Gabrielse, C., V. Angelopoulos, A. Runov, and D. L. Turner (2014), Statistical characteristics of

particle injections throughout the equatorial magnetotail, Journal of Geophysical Research: Space Physics, 119, 2512-2535, doi:10.1002/2013JA019638

Henderson, M. G., Reeves, G. D., and Murphree, J. S. (1998), Are north-south aligned auroral structures an ionospheric manifestation of bursty bulk flows?, Geophysical Research Letters, 25, 3737-3740, doi:10.1029/98GL02692

Henderson, M. G., Kepko, L., Spence, H. E., Connors, M., Sigwarth, J. B., Frank, L. A., Singer,

H.,J., and Yumoto, K. (2002), The evolution of north-south aligned auroral forms into auroral torch structures: The generation of omega bands and Ps6 pulsations via flow bursts, in the Proceedings of the Sixth International Conference on Substorms, edited by

R. M. Winglee, University of Washington, Seattle, WA, ISBN:0971174032 9780971174030

Kadokura, A., H. Yamagishi, N. Sato, K. Nakano, and M. C. Rose (2008), Unmanned magnetometer network observation in the $44^{\text {th }}$ Japanese Antarctic Research

Expedition:

Initial results and an event study on auroral substorm evolution, Polar Science 2, 223235, doi:10.1016/j.polar.2008.04.002

Kauristie, K., Sergeev, V. A., Kubyshkina, M., Pulkkinen, T. I., Angelopoulos, V., Phan, T., Lin,

R. P., and Slavin, J. A. (2000), Ionospheric current signatures of transient plasma

flows, Journal of Geophysical Research, 105, 10,677-10,690,

doi:10.1029/1999JA900487

Kim, H., X. Cai, C. R. Clauer, B. S. R. Kunduri, J. Matzka, C. Stolle, and D. R. Weimer (2013), 
Geomagnetic response to solar wind dynamic pressure impulse events at high-latitude conjugate points, J. Geophys. Res. Space Physics, 118, 6055-6071,

doi:10.1002/jgra.50555.

Kozyreva, O. V., V. A. Pilipenko, V. B. Belakhovsky, and Ya. A. Sakharov (2018), Ground geomagnetic field and GIC response to March 17, 2015 storm, Earth, Planets and Space,

70:157, doi:10.1186/s40623-018-0933-2

Lanzerotti, L. J., A. Wolfe, N. Trivedi , C. G. Maclennan, and L. V. Medford (1990), Magnetic

impulse events at high latitudes: Magnetopause and boundary layer plasma processes, Journal of Geophysical Research, 95, 97-107, doi:10.1029/JA095iA01p00097

Liou, K., T. Sotirelis, and E. J. Mitchell (2018), North-south asymmetry in the geographic location of auroral substorms correlated with ionospheric effects, Scientific Reports,

8 ,

17230, doi:10.1038/s41598-018-35091-2

Liu, J., V. Angelopoulos, X.-Z. Zhou, and A. Runov (2014), Magnetic flux transport by dipolarizing flux bundles, Journal of Geophysical Research: Space Physics, 119, 909

926, doi:10.1002/2013JA019395

Liu, J., L. R. Lyons, W. E. Archer, B. Gallardo-Lacourt, Y. Nishimura, Y. Zou, C. Gabrielse, and

J. M. Weygand (2018), Flow shears at the poleward boundary of omega bands observed

during conjunctions of Swarm and THEMIS ASI, Geophysical Research Letters, 45, 1218-1227, doi:10.1002/2017GL076485

Lyons, L. R., Nishimura, Y., Xing, X., Runov, A., Angelopoulos, V., Donovan, E., and Kikuchi,

T. (2012), Coupling of dipolarization front flow bursts to substorm expansion phase phenomena within the magnetosphere and ionosphere, Journal of Geophysical Research,

117, A02212, doi:10.1029/2011JA017265

Lysak, R. L. (1990), Electrodynamic coupling of the magnetosphere and ionosphere, Space Science Reviews, 52, 33-87, doi:10.1007/BF00704239 
Newell, P. T., T. Sotirelis, and S. Wing (2009), Diffuse, monoenergetic, and broadband aurora:

The global precipitation budget, Journal of Geophysical Research, 114, A09207, doi:10.1029/2009JA014326.

Newell, P. T., T. Sotirelis, and S. Wing (2010), Seasonal variations in diffuse, monoenergetic,

and broadband aurora, Journal of Geophysical Research, 115, A03216, doi:10.1029/2009JA014805.

Newell, P. T., and J. W. Gjerloev (2011a), Evaluation of SuperMAG auroral electrojet indices as

indicators of substorms and auroral power, Journal of Geophysical Research, 116, A12211, doi:10.1029/2011JA016779

Newell, P. T., and J. W. Gjerloev (2011b), Substorm and magnetosphere characteristic scales inferred from the SuperMAG auroral electrojet indices, Journal of Geophysical Research,

116, A12232, doi:10.1029/2011JA016936

Newell, P. T., Liou, K., Zhang, Y., Sotirelis, T., Paxton, L. J., and Mitchell, E. J. (2014), OVATION Prime-2013: Extension of auroral precipitation model to higher disturbance

levels, SpaceWeather, 12, 368-379, doi:10.1002/2014SW001056

Ngwira, C. M., A. A. Pulkkinen, E. Bernabeu, J. Eichner, A. Viljanen, and G. Crowley (2015),

Characteristics of extreme geoelectric fields and their possible causes: Localized peak

enhancements, Geophysical Research Letters, 42, 6916-6921,

doi:10.1002/2015GL065061

Ngwira C. M., D. G. Sibeck, M. D. V. Silveira, M. Georgiou, J. M. Weygand, Y. Nishimura, and

D. Hampton (2018), A study of intense local $d B / \mathrm{d} t$ variations during two geomagnetic Storms, Space Weather, 16, 676-693, doi:10.1029/2018SW001911.

Ngwira, C. M., and A. A. Pulkkinen (2019), An introduction to geomagnetically induced currents (2019), in Geomagnetically Induced Currents from the Sun to the Power

Grid, 
Geophysical Monograph Series, 244, edited by J. L. Gannon, A. Swidinsky, and Z. $\mathrm{Xu}$,

American Geophysical Union, Washington, D.C., 3-14, doi:10.1002/9781119434412.ch1

Nikitina, L., Trichtchenko, L., and Boteler, D. H. (2016), Assessment of extreme values in geomagnetic and geoelectric field variations for Canada. Space Weather, 14, 481494,

doi:10.1002/2016SW001386

Opgenoorth, H. J., Oksman, J., Kaila, K. U., Nielsen, E., and Baumjohann, W. (1983),

Characteristics of eastward drifting omega bands in the morning sector of the auroral oval, Journal of Geophysical Research, 88, 9171-9185,

doi:10.1029/JA088iA11p09171

Palin, L., C. Jacquey, H. Opgenoorth, M. Connors, V. Sergeev, J.-A. Sauvaud, R. Nakamura, G. D. Reeves, H. J. Singer, V. Angelopoulos, and L. Turc (2015), Three-dimensional current systems and ionospheric effects associated with small dipolarization fronts, $J$.

Geophys. Res. Space Physics, 120, 3739-3757, doi:10.1002/2015JA021040

Paxton, L. J., C.-I. Meng, G. H. Fountain, B. S. Ogorzalek, E. H. Darlington, J. Goldstein, and $\mathrm{K}$.

Peacock (1993), "SSUSI - Horizon-to-horizon and limb-viewing spectrographic imager

for remote sensing of environmental parameters", Proc. SPIE 1764, Ultraviolet

Technology IV, 161 (January 22, 1993), doi:10.1117/12.140846

Partamies, N., Weygand, J. M., and Juusola, L. (2017), Statistical study of auroral omega bands,

Annales Geophysicae, 35, 1069-1083, doi:10.5194/angeo-35-1069-2017

Pilipenko, V. A., Fedorov, E. N., Hartinger, M. D., and Engebretson, M. J. (2019),

Electromagnetic fields of magnetospheric ULF disturbances in the ionosphere:

Current/voltage Dichotomy, Journal of Geophysical Research: Space Physics, 124, 109

121, doi:10.1029/2018JA026030

Pulkkinen, A., E. Bernabeu, J. Eichner, A. Viljanen, and C. Ngwira (2015), Regional-scale high- 
latitude extreme geoelectric fields pertaining to geomagnetically induced currents, Earth,

Planets, and Space, 67, 93, doi:10.1186/s40623-015-0255-6

Robinson, R. M., R. R. Vondrak, K. Miller, T. Dabbs, and D. Hardy (1987), On calculating ionospheric conductances from the flux and energy of precipitating electrons, Journal of

Geophysical Research, 92, 2565-2569, doi:10.1029/JA092iA03p02565

Sato, N., Yukimatu, A. S., Tanaka, Y., and Hori, T. (2017), Morphologies of omega band auroras, Earth, Planets and Space, 69, 103,

Sergeev, V. A., Liou, K., Meng, C.-I., Newell, P. T., Brittnacher, M., Parks, G., and Reeves, G.

D, (1999), Development of auroral streamers in association with localized impulsive injections to the inner magnetotail, Geophysical Research Letters, 26, 417-420, doi:10.1029/1998GL900311

Solovyev, S. I., Baishev, D. G., Barkova, E. S., Engebretson, M. J., Posch, J. L., Hughes, W. J.,

Yumoto, K., and Pilipenko, V. A. (1999), Structure of disturbances in the dayside and nightside ionosphere during periods of negative interplanetary magnetic field $\mathrm{Bz}$,

\section{Journal}

of Geophysical Research, 104, 28,019-28,039, doi:10.1029/1999JA900286

Sotirelis, T., H. Korth, S.-Y. Hsieh, Y. Zhang, D. Morrison, and L. Paxton, (2013), Empirical relationship between electron precipitation and far-ultraviolet auroral emissions from DMSP observations, Journal of Geophysical Research: Space Physics, 118, 1203 1209 ,

doi:10.1002/jgra.50157

Viljanen A. (1997), The relation between geomagnetic variations and their time derivatives and

implications for estimation of induction risks, Geophysical Research Letters, 24, 631634, doi:10.1029/97GL00538

Viljanen, A., Nevanlinna, H., Pajunpää, K., and Pulkkinen, A. (2001), Time derivative of the horizontal geomagnetic field as an activity indicator, Annales Geophysicae, 19(9), 1107

1118, doi:10.5194/angeo-19-1107-2001 
Viljanen, A., E. I. Tanskanen, and A. Pulkkinen (2006), Relation between substorm characteristics

and rapid temporal variations of the ground magnetic field, Annales Geophysicae, 24, $725-$

733, doi:10.5194/angeo-24-725-2006.

Viljanen, A., and Tanskanen, E. (2011), Climatology of rapid geomagnetic variations at high latitudes over two solar cycles, Annales Geophysicae, 29, 1783-1792, doi:10.5194/angeo-29-1783-2011

Weygand, J. M., Kivelson, M. G., Frey, H. U., Rodriguez, J. V., Angelopoulos, V., Redmon, R., and Amm, O. (2015), An interpretation of spacecraft and ground based observations of multiple omega band events, Journal of Atmospheric and Solar-Terrestrial Physics, 133 ,

185-204, doi:10.1016/j.jastp.2015.08.014

Zesta, E., Lyons, L., and Donovan, E. (2000), The auroral signature of Earthward flow bursts observed in the magnetotail, Geophysical Research Letters, 27, 3241-3244, doi:10.1029/2000GL000027

Zesta, E., Lyons, L., Wang, C.-P., Donovan, E., Frey, H., and Nagai, T. (2006), Auroral poleward boundary intensifications (PBIs): Their two-dimensional structure and associated dynamics in the plasma sheet, Journal of Geophysical Research, 111,

\section{A05201,}

doi:10.1029/2004JA010640 
Table 1. Magnetometer Stations Used in This Study

Northern Hemisphere

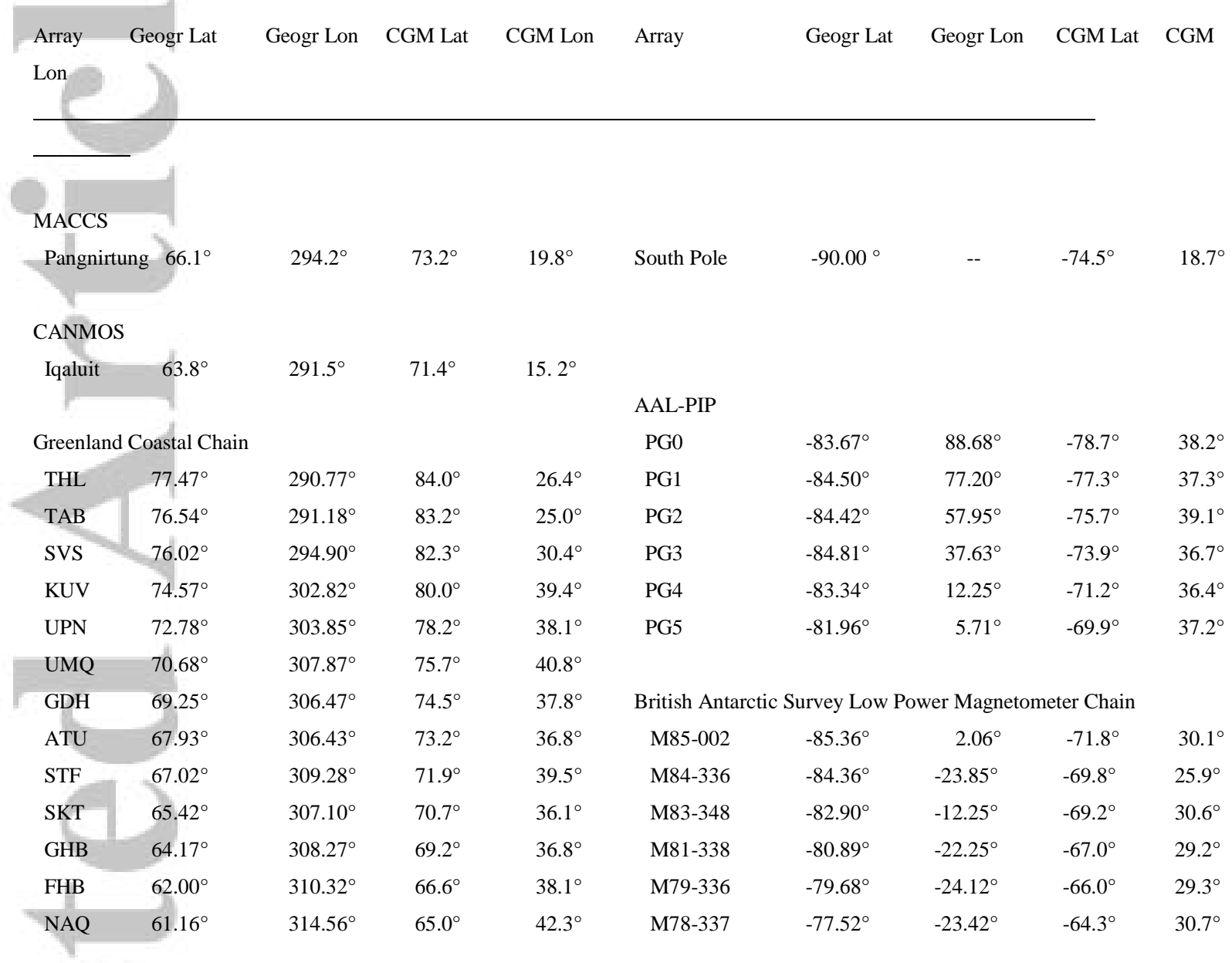

Note: Corrected geomagnetic (CGM) coordinates were calculated for epoch 2016 (using http://sdnet.thayer.dartmouth.edu/aacgm/aacgm_calc.php\#AACGM). 
Table 2. The maximum $|\mathrm{dB} / \mathrm{dt}|$ values for each component for each of the stations shown during each of the intervals presented here. Only X component data were available at SPA during two events.

\begin{tabular}{|c|c|c|c|c|}
\hline Station & 15 Jan 2018 & 16 Mar 2016 & 8 May 2016 & 13 Мay 2015 \\
\hline SPA & $-15.1, \quad-, \quad-$ & $7.5,-12.1, \quad 4.9$ & & $-3.3 . \quad-, \quad-$ \\
\hline PGG & $-9.1, \quad 5.7,4.3$ & $-6.3,3.3,4.4$ & & $3.2, \quad 2.5, \quad 1.9$ \\
\hline IQA & & $2.0, \quad 1.7, \quad 2.0$ & & $-3.8, \quad 3.4, \quad 4.9$ \\
\hline PG2 & $4.9, \quad 2.6,-3.1$ & $4.2,-3.3, \quad 3.8$ & & $\begin{array}{lll}-3.6, & 4.3, & 2.7\end{array}$ \\
\hline PG3 & $-8.1,6.4,-9.8$ & $8.6, \quad 4.2, \quad 4.8$ & & $5.4,-3.4,-5.7$ \\
\hline PG4 & & $-13.2,-11.4,13.6$ & & $5.2, \quad 5.2,-6.1$ \\
\hline PG5 & $-8.0, \quad 5.5, \quad 7.8$ & $-16.2,13.3,-12.0$ & & \\
\hline M85 & & & & $3.2, \quad 1.9, \quad 1.9$ \\
\hline M84 & & $-25.7,12.7, \quad 5.2$ & & \\
\hline M83 & & & & $7.7, \quad 6.7, \quad 4.2$ \\
\hline M81 & & $15.6,8.6, \quad 9.6$ & $-12.9,-3.2,-4.0$ & $-7.7,-10.7,-6.1$ \\
\hline M79 & $3.4,-2.3, \quad 1.2$ & $15.8, \quad 6.3, \quad 3.4$ & $-37.7,13.7,19.5$ & \\
\hline M78 & $4.5, \quad 3.8,-3.3$ & & $-14.4, \quad 9.1,10.3$ & \\
\hline UMQ & $-8.8, \quad 3.8, \quad 4.9$ & & & $2.1, \quad 1.5, \quad 1.6$ \\
\hline GDH & $-10.0,-10.6,-12.7$ & $3.0, \quad 2.2,-4.5$ & & $-2.8, \quad 1.6,2.0$ \\
\hline STF & $-12.8,-7.0,-8.9$ & $-7.2,-5.6,-7.1$ & & $3.1, \quad 6.0,-3.7$ \\
\hline SKT & $-11.3,-7.5,-13.5$ & $-6.4,-4.7, \quad 9.8$ & & $2.9, \quad 6.3,6.3$ \\
\hline GHB & $-4.5, \quad 5.0, \quad-8.3$ & $-8.1,-5.9, \quad-$ & $-2.4, \quad 1.6, \quad-$ & $3.4, \quad 7.0,-5.9$ \\
\hline FHB & $3.2, \quad 3.5,-4.6$ & $6.6,-3.0, \quad 5.8$ & $-6.7, \quad 6.5,-9.6$ & $-4.7,7.0,-8.1$ \\
\hline NAQ & $4.3, \quad 2.1, \quad-2.2$ & $-3.8,-3.0,-3.3$ & $-7.5,-6.5,-6.4$ & $-9.2,10.5,-5.3$ \\
\hline
\end{tabular}

Table 3. Half-amplitude latitudinal and longitudinal falloff distances between adjacent station pairs for the MPE occurring near 2105 UT on 8 May 2016 in Antarctica and Greenland, respectively.

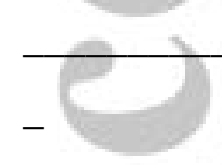

BAS LPM

Conjugate
BAS LPM - Greenland

Greenland

$$
\begin{array}{ll}
\text { M81-FHB } & 446 \mathrm{~km} \\
\text { M79-FHB } & 262 \mathrm{~km}
\end{array}
$$




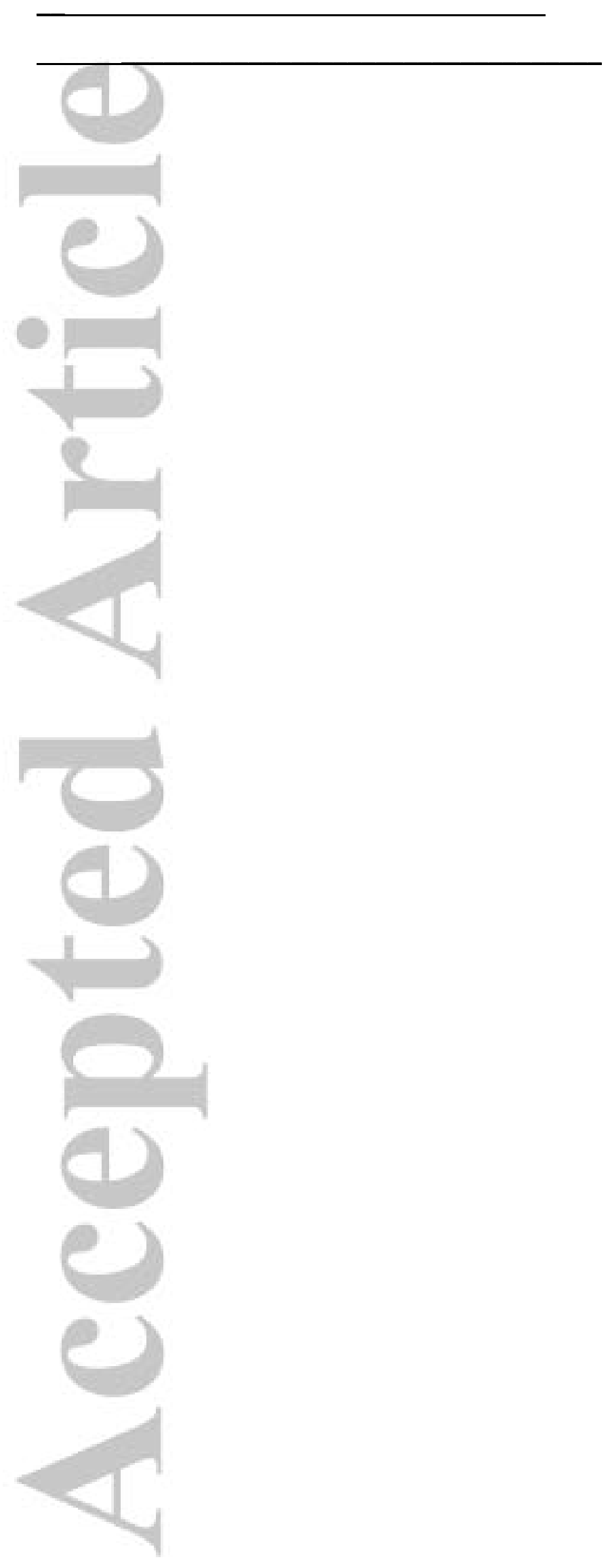

(C2020 American Geophysical Union. All rights reserved. 

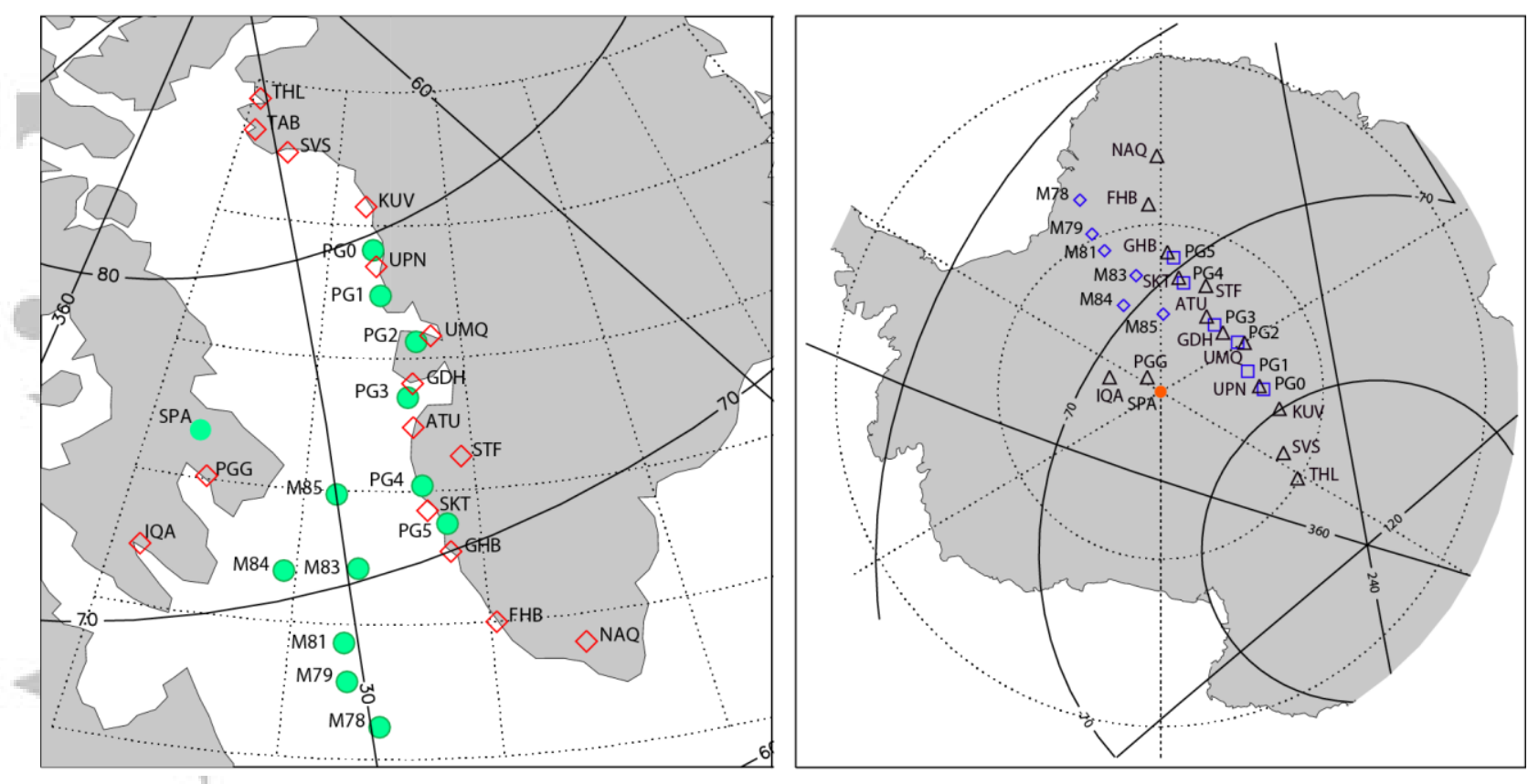

Figure 1. Maps showing the location of ground magnetometer stations used for this study. a)

Map of Arctic Canada and Greenland, showing stations in the northern hemisphere

(diamonds) and the conjugate mapped locations of southern hemisphere stations (green circles). b) Map of Antarctica, showing stations in the southern hemisphere (diamonds, squares, and red circle) and the conjugate mapped locations of northern hemisphere stations

(triangles). Solid lines show corrected geomagnetic coordinates 

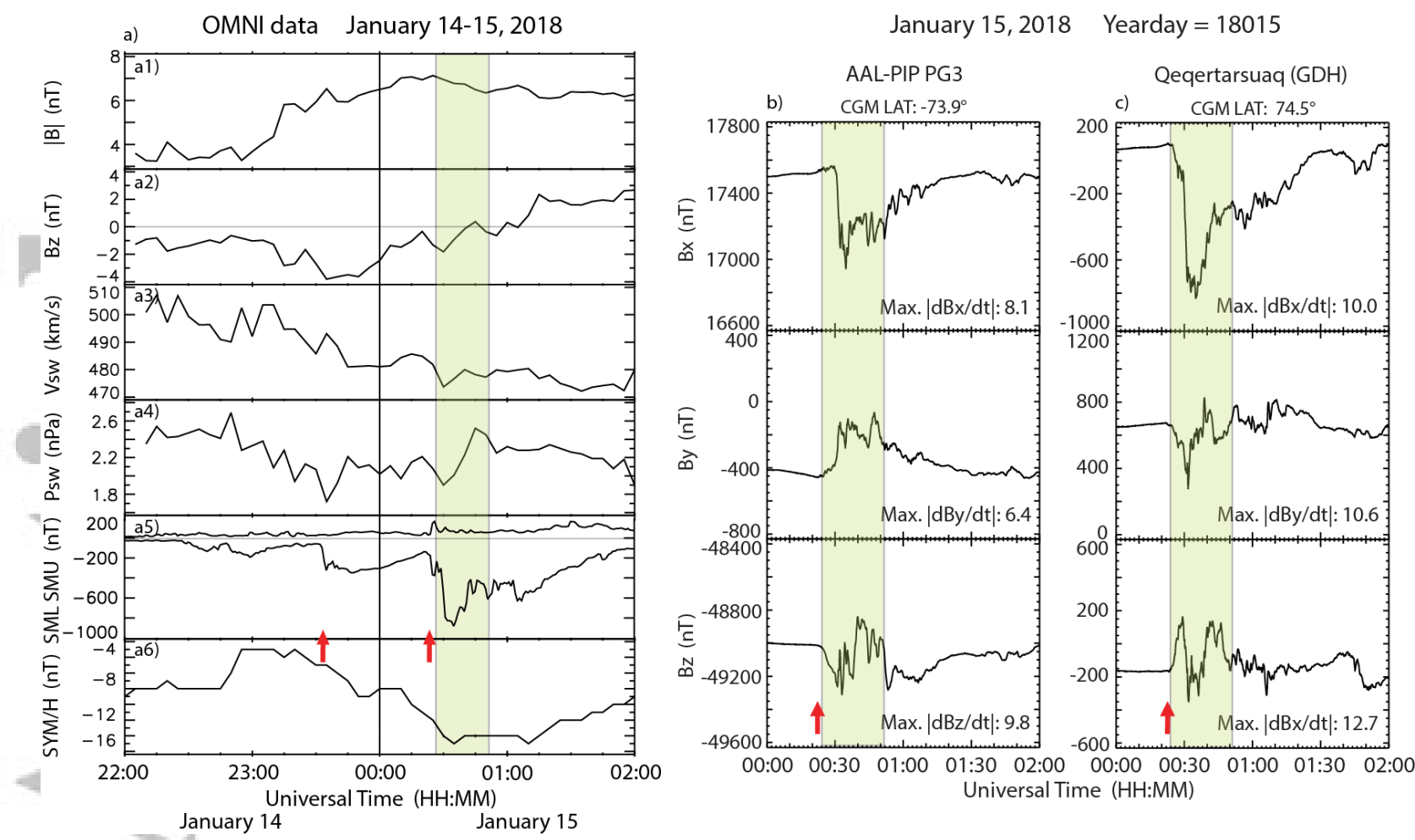

Figure 2. Panel a shows OMNI data that provide the interplanetary and magnetospheric context for the MPE event on January 15, 2018. Panels a1 and a2 show the magnitude $|\mathrm{B}|$ and north-south component $\mathrm{Bz}$ of the interplanetary magnetic field (IMF), respectively. Panel a3 shows the solar wind flow speed, Vsw, and panel a4 shows the solar wind dynamic pressure, Psw. Panel a5 shows the SuperMAG SML and SMU indices, and panel a6 shows the SYM/H index. Panels $b$ and $c$ show two-hour excerpts of magnetograms from AAL-PIP PG3, Antarctica, and Qeqertarsuak (GDH), Greenland, respectively. The shaded region in each panel, from 0024 to 0052 UT, highlights the large magnetic perturbation observed at both stations, and the red arrows indicates the times of the only substorm onsets occurring within 3 hours prior to the MPE interval. 


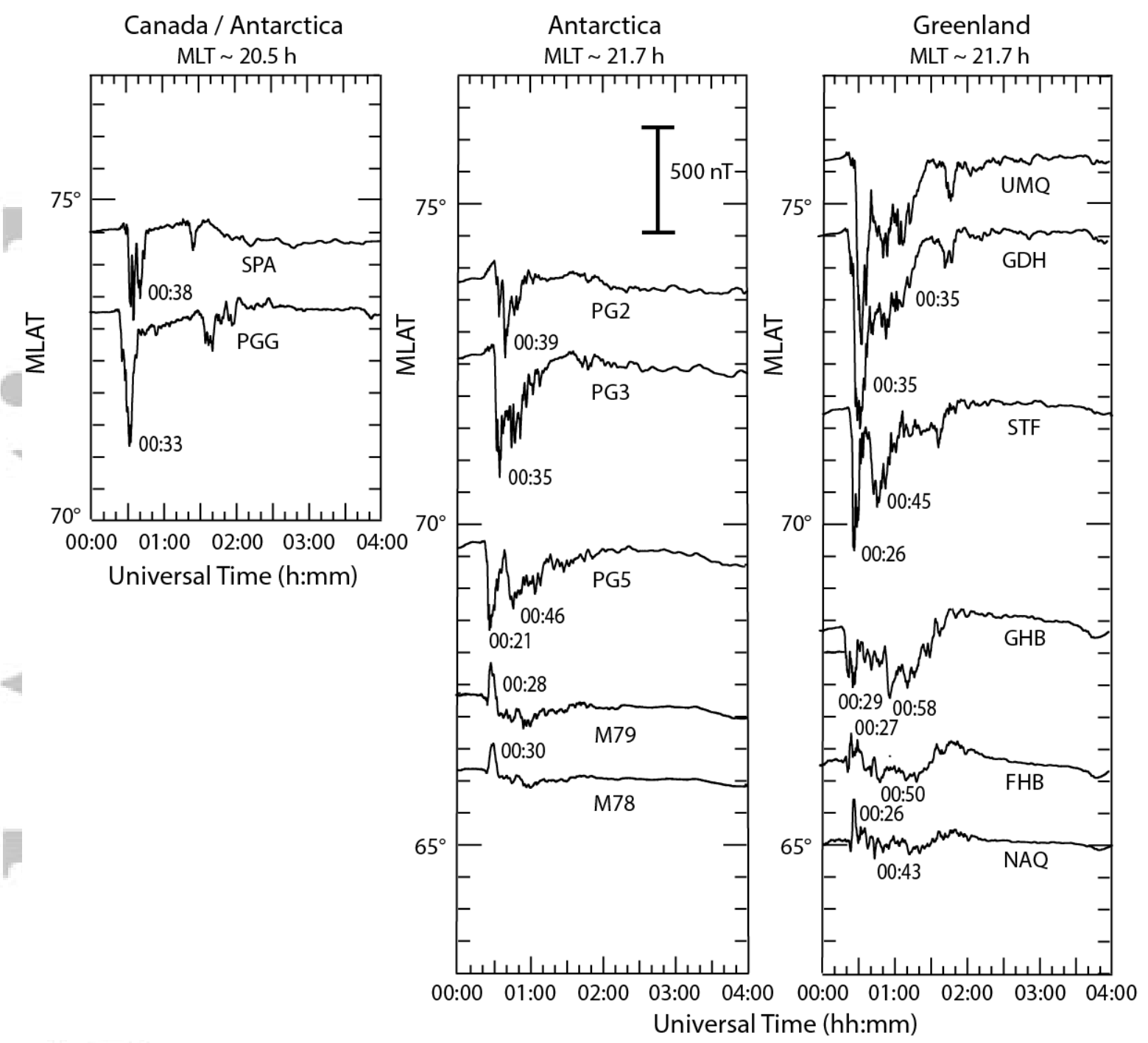

Figure 3. Four-hour excerpts of Bx component (north-south) magnetograms for January 15, 2018 from a) SPA and PGG, b) PG2, PG3, PG5, M79, and M78, and c) UMQ, GDH, STF, GHB, FHB, and NAQ), arranged vertically in order of magnetic latitude and horizontally in order of magnetic local time / magnetic longitude. At each station, the time of maximum $|\Delta \mathrm{Bx}|$ perturbations is shown. 


\section{January 15, $2018 \quad 18015 \sim 00: 35$ UT}

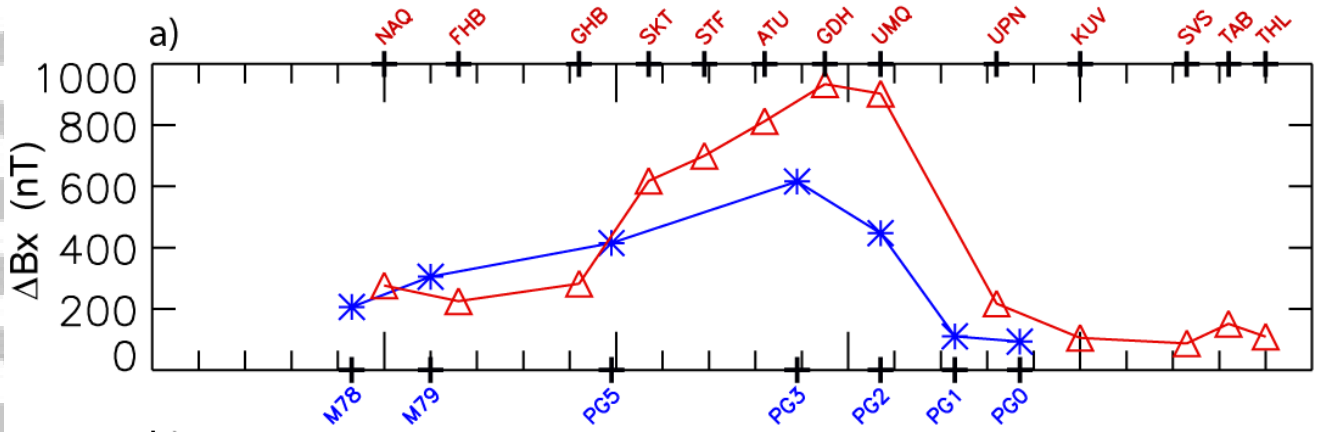

b)

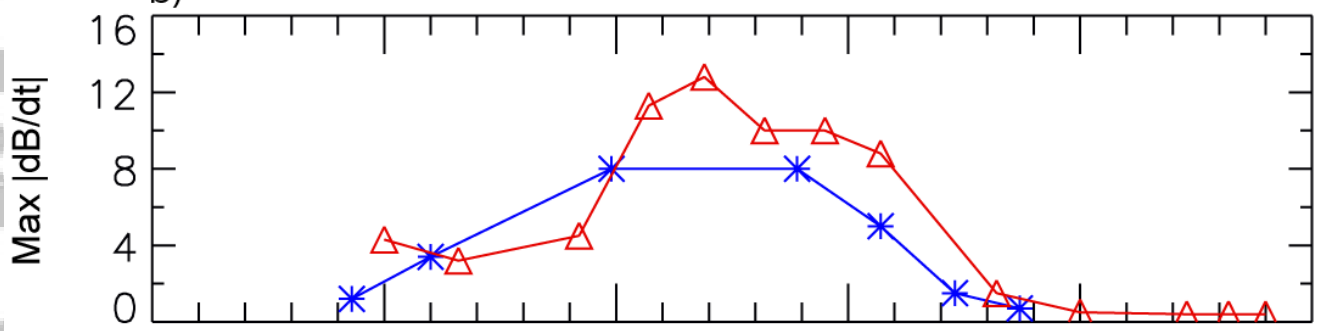

c)

AMIE Model Conductances

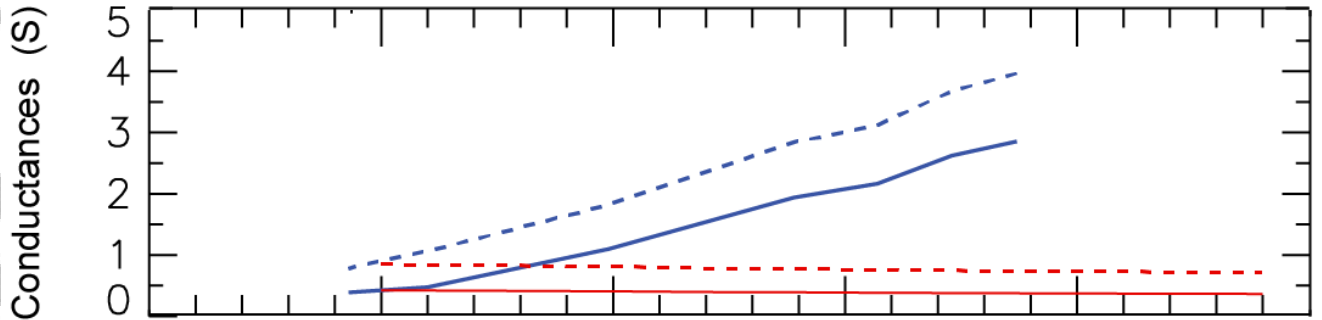

d) AMIE Model plus Ovation Prime Model Conductances

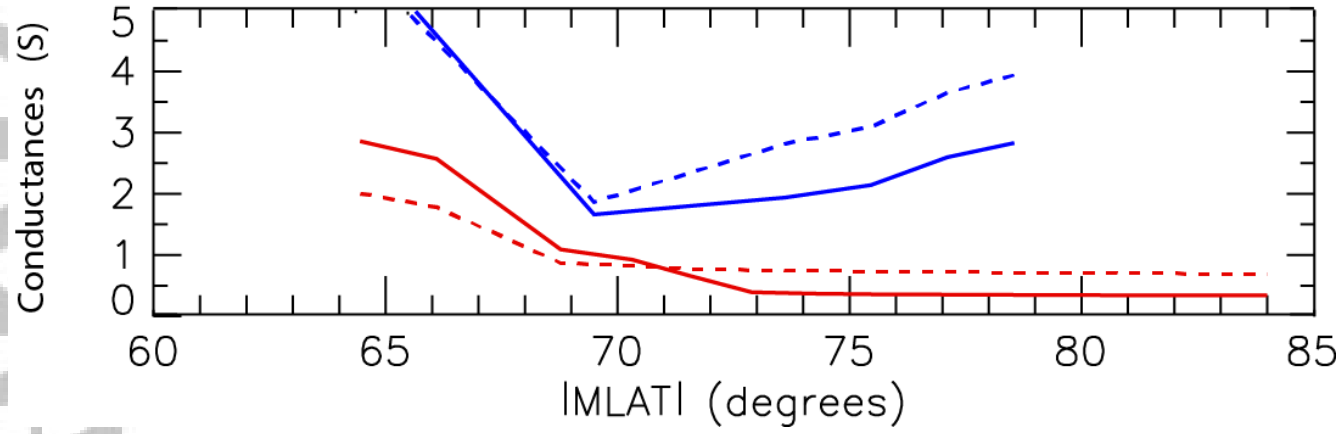

Figure 4. Plots of the perturbation amplitude $\Delta \mathrm{Bx}$ (panel a), the maximum derivative in any component (panel b), and two models of the ionospheric Pedersen and Hall conductances (panels $\mathrm{c}$ and d), as a function of magnetic latitude, observed at every available station in the West Greenland Coastal Array (red) and the AAL-PIP and BAS LPM arrays (blue) for the MPE at $\sim 0035$ UT January 15, 2018. Solid lines denote Pedersen conductances $\left(\Sigma_{P}\right)$ and dashed lines Hall conductances $\left(\Sigma_{H}\right)$. 

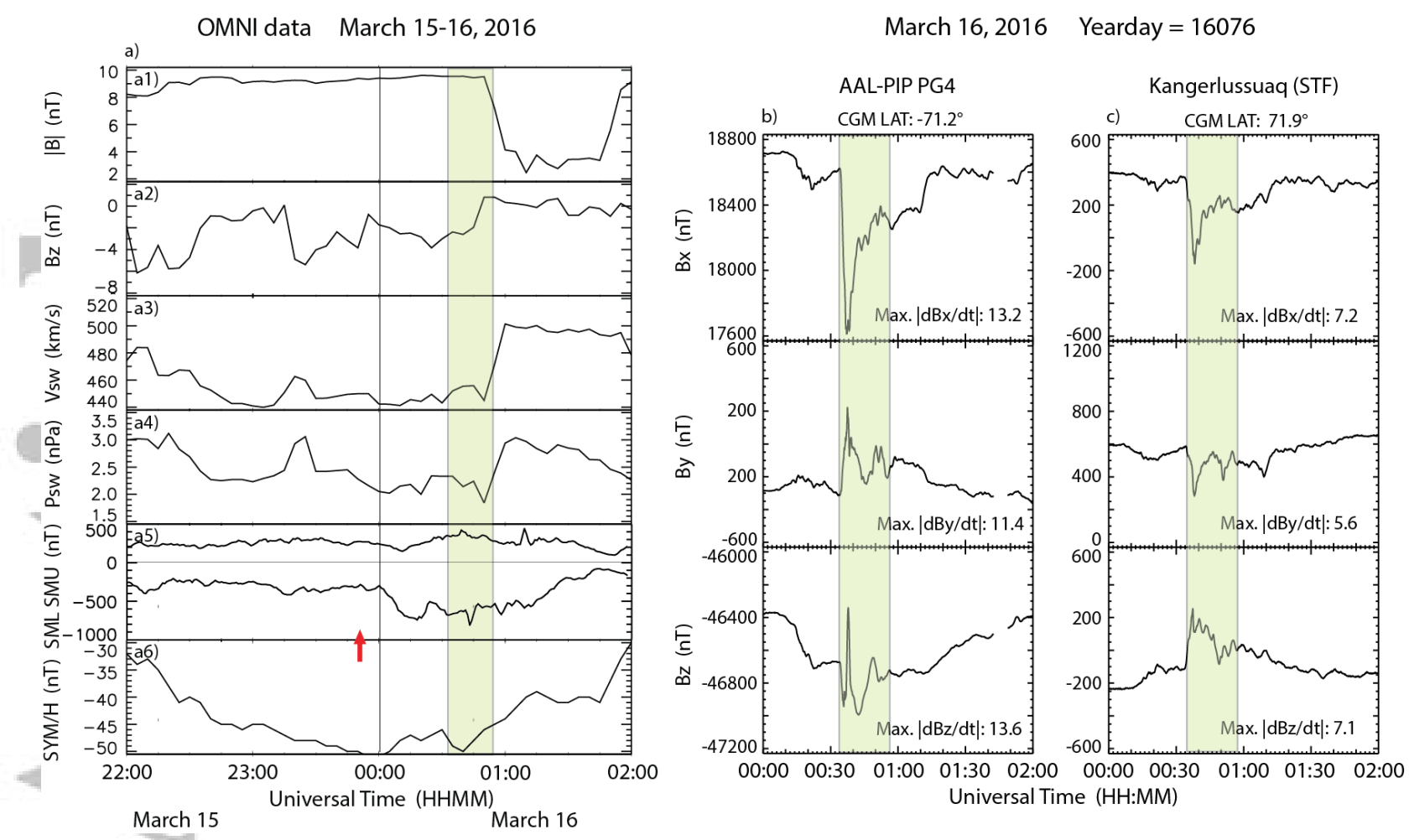

Figure 5. Panel a shows OMNI data for the MPE event on March 16, 2016, as in Figure 2.

Panels b and c show two-hour excerpts of magnetograms from AAL-PIP PG4, Antarctica, and Kangerlussuaq (STF), Greenland, respectively. The shaded region in each panel, from 0034 to 0057 UT, highlights the large magnetic perturbation observed at both stations, and the red arrow indicates the time of the only substorm onset occurring within 3 hours prior to the MPE interval. 

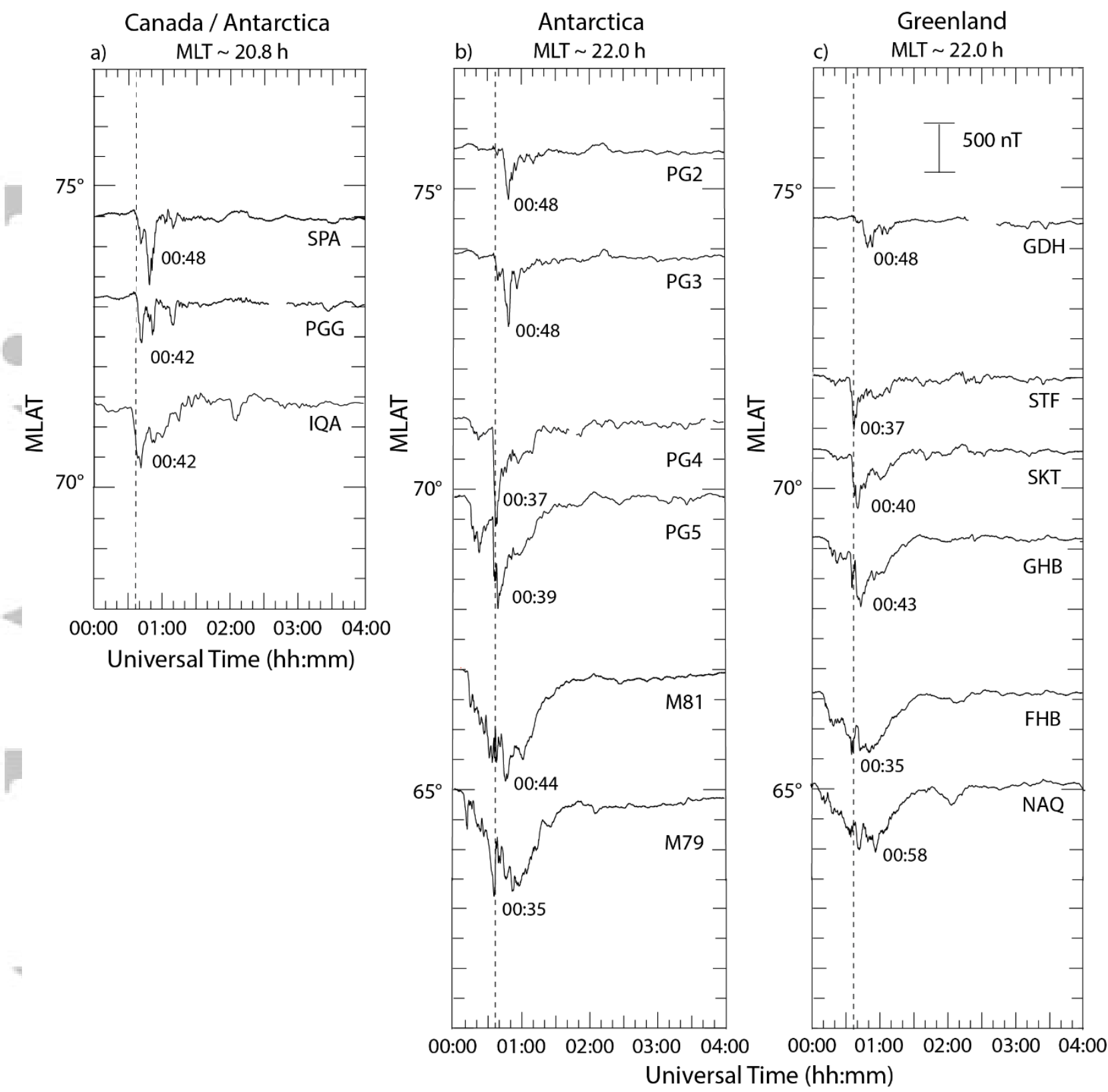

Figure 6. Four-hour excerpts of Bx component (north-south) magnetograms for March 16, 2016, as in Figure 3. a) SPA, PGG, and IQA, b) PG2, PG3, PG4, PG5, M81, and M79, and c) GDH, STF, SKT, GHB, FHB, and NAQ. At each station, the time of maximum $|\Delta \mathrm{Bx}|$ perturbations is shown. The vertical dashed lines mark 00:37 UT, the time of minima in the Bx component at PG4, M84 (not shown), and STF. 
March 16, $2016 \quad 16076 \quad 00: 38$ and 00:48 UT
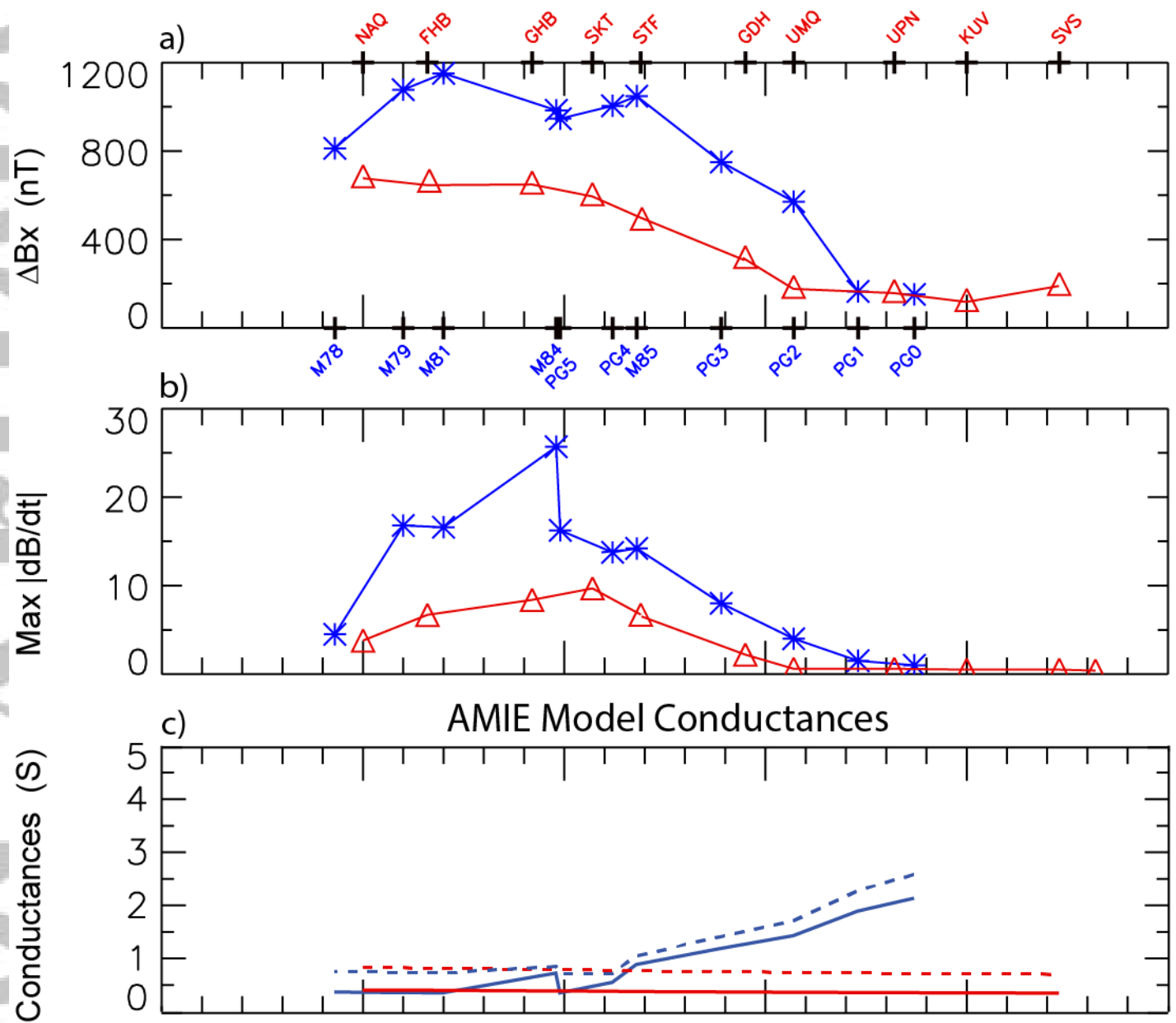

d) AMIE Model plus Ovation Prime Model Conductances

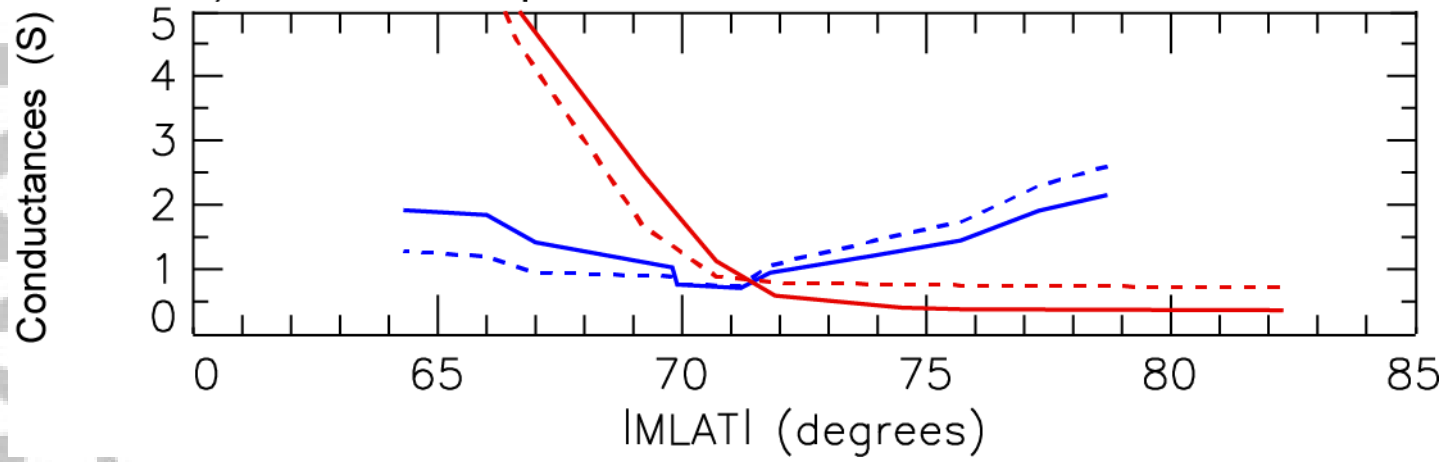

Figure 7. Plots of the perturbation amplitude $\Delta \mathrm{Bx}$ (panel a), the maximum derivative in any component (panel b), and two models of the ionospheric Pedersen and Hall conductances (panels c and d), as a function of magnetic latitude as in Figure 4, for the MPEs near $~ 0040$ UT March 16, 2016. Solid lines denote Pedersen conductances $\left(\Sigma_{P}\right)$ and dashed lines Hall conductances $\left(\Sigma_{H}\right)$. 

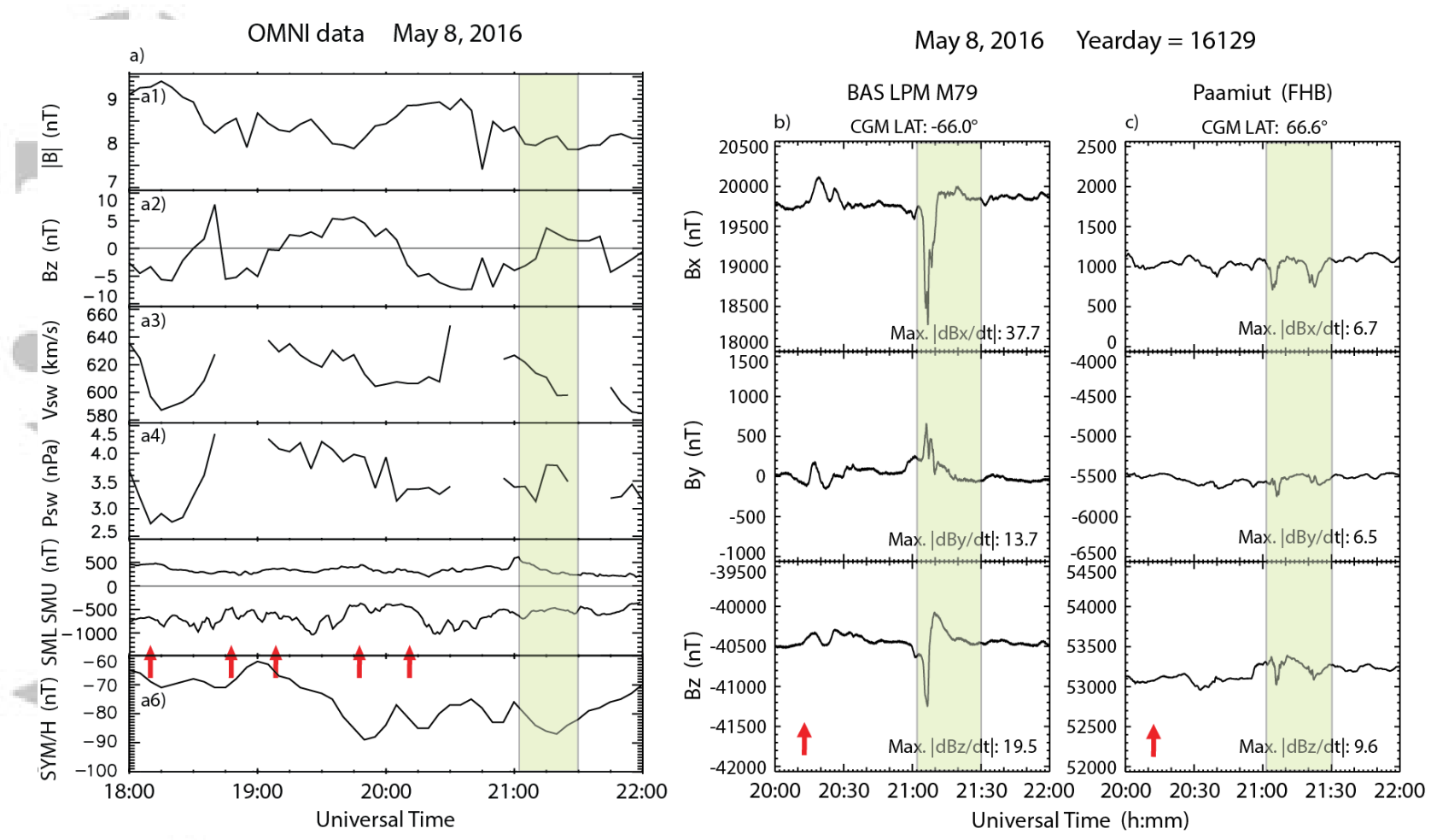

Figure 8. Panel a shows OMNI data for the MPE event on May 8, 2016, as in Figure 2.

Panels $b$ and $c$ show two-hour excerpts of magnetograms from BAS LPM M79, Antarctica, and Paamiut (FHB), Greenland, respectively. The shaded region in each panel, from 2102 to 2130 UT, highlights the large magnetic perturbations observed at both stations, and the red arrows indicate the times of all substorm onsets occurring within 3 hours prior to the MPE interval. 


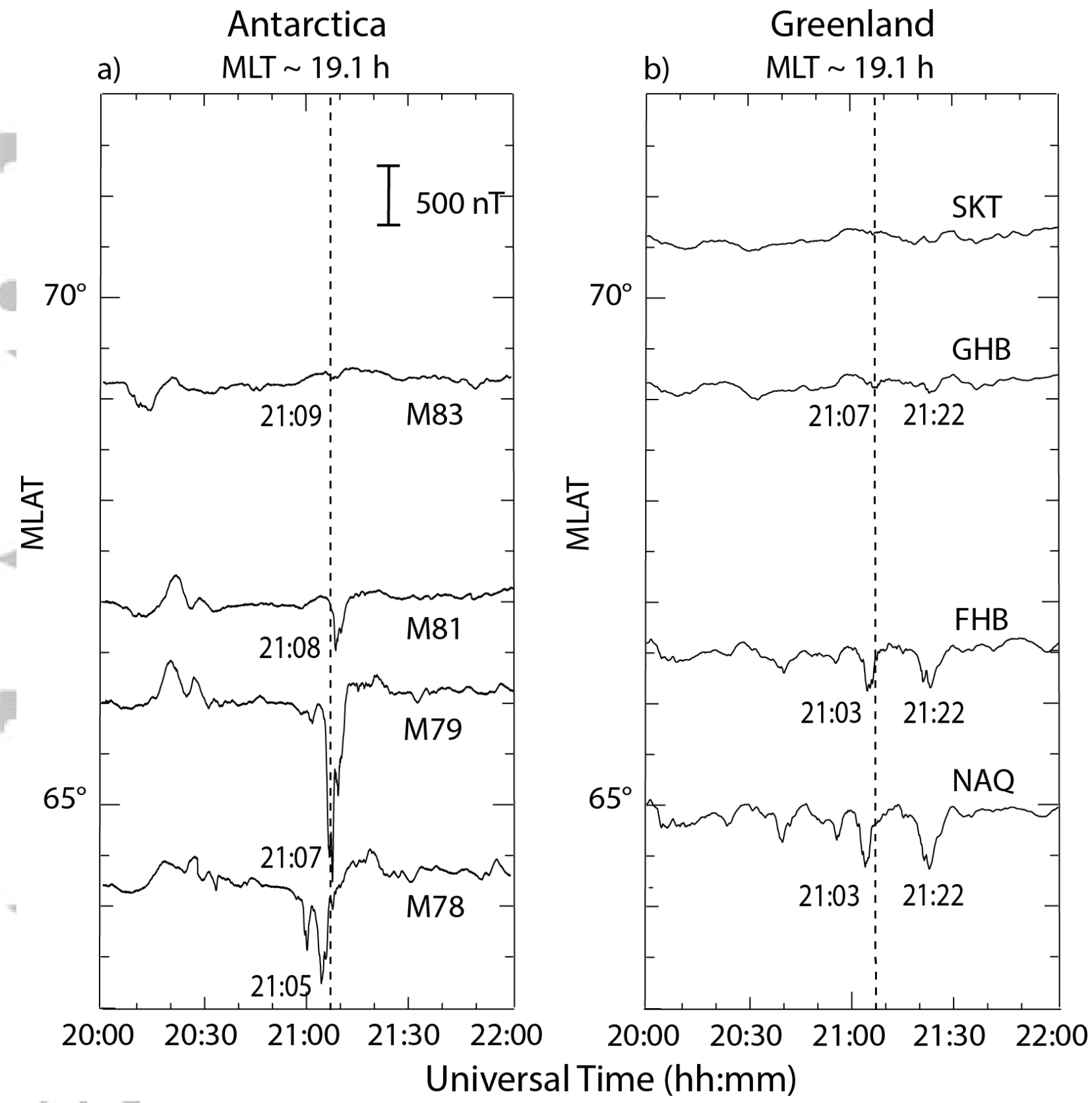

Figure 9. Two-hour excerpts of Bx component (north-south) magnetograms for May 8, 2016, as in Figure 3. a) M83, M81, M79, and M78, and b) SKT, GHB, FHB, and NAQ. At each station, the time of maximum $|\Delta \mathrm{Bx}|$ perturbations is shown. The vertical dashed lines mark 21:07 UT, the time of minima in the Bx component at GHB and M79. 


\section{May 8, $201616129 \sim 21: 08$ UT}

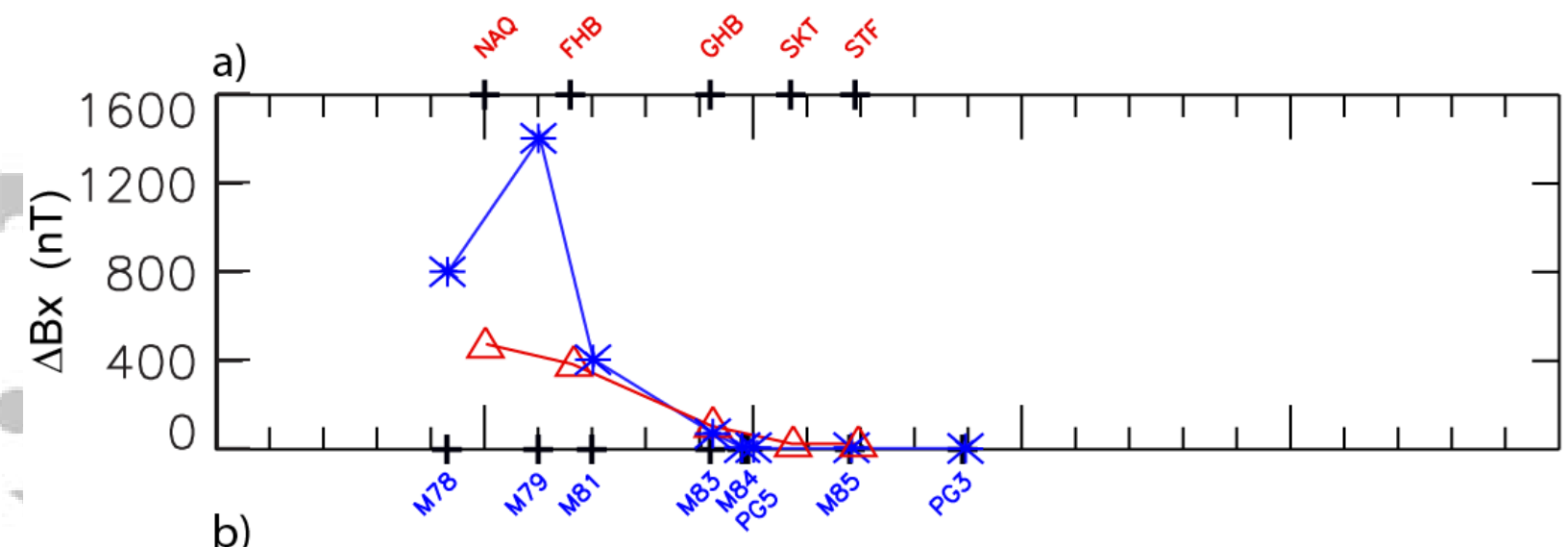

b)
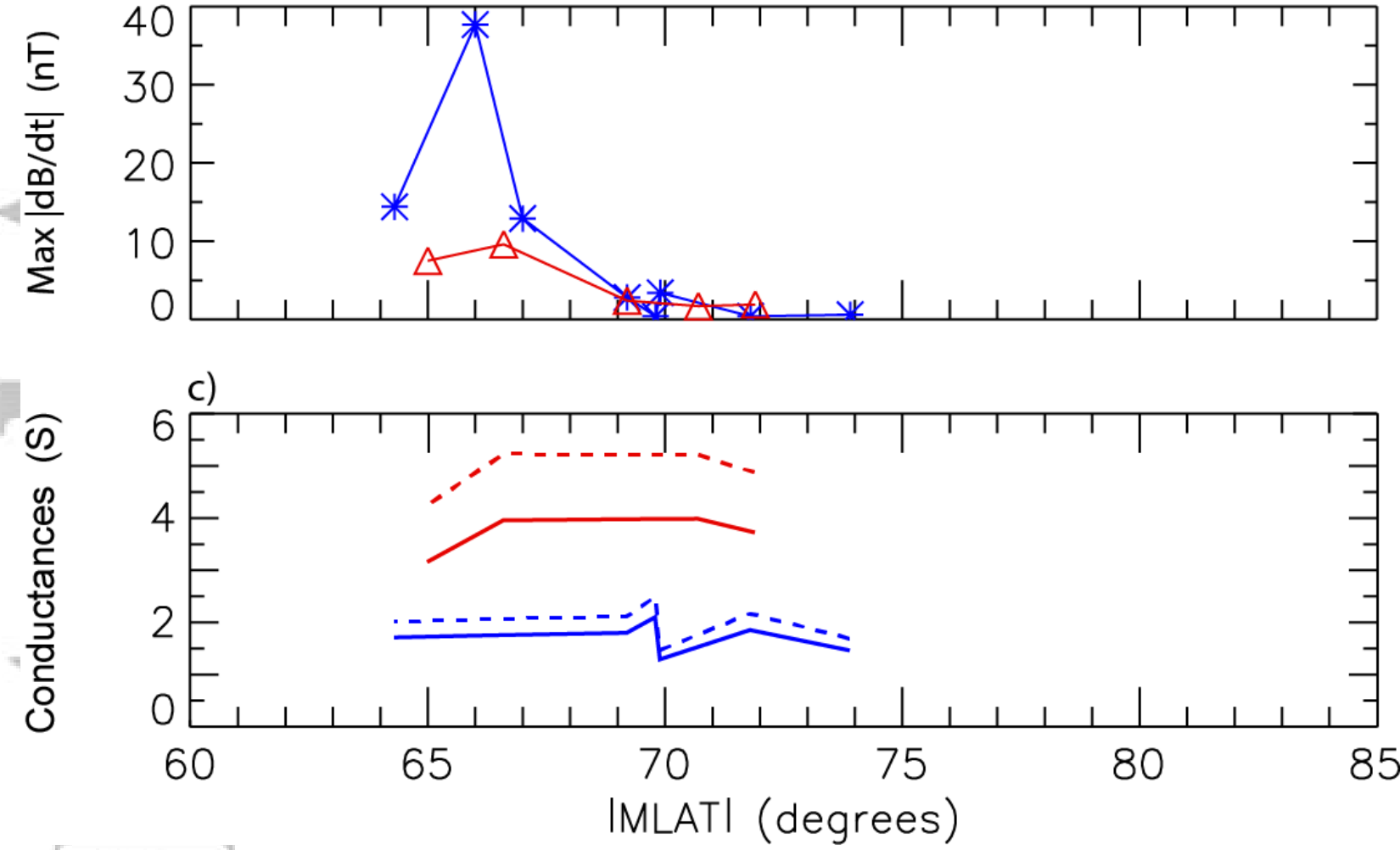

Figure 10. Plots of the perturbation amplitude $\Delta \mathrm{Bx}$ (panel a), the maximum derivative in any component (panel b), and a model of the ionospheric Pedersen and Hall conductances (panel c), as a function of magnetic latitude as in Figure 4, for the MPE at 2108 UT May 8, 2016.

Solid lines denote Pedersen conductances $\left(\Sigma_{P}\right)$ and dashed lines Hall conductances $\left(\Sigma_{H}\right)$. 
$\mathrm{C}$
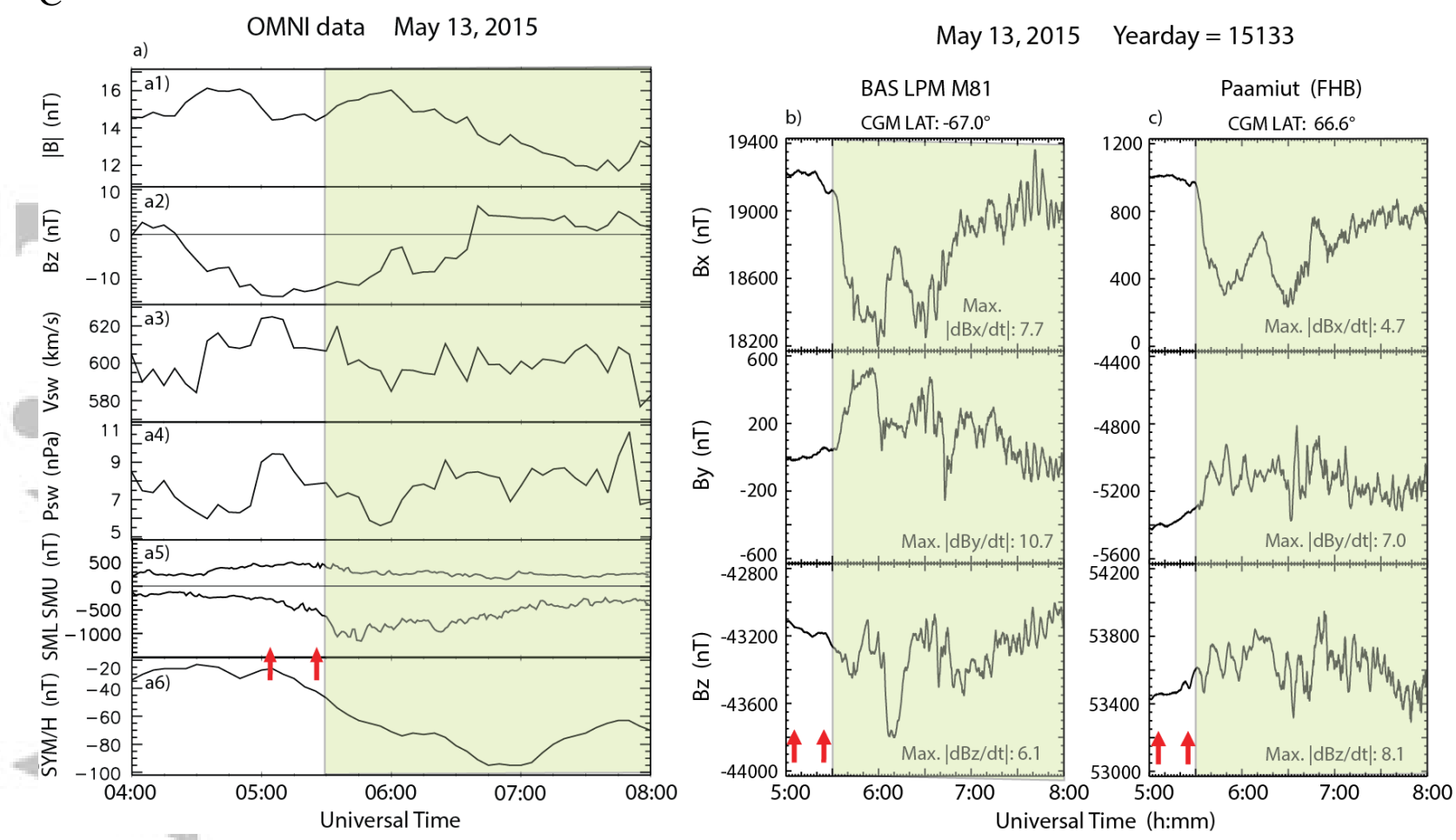

Figure 11. Panel a shows OMNI data for the MPE event on May 13, 2015, as in Figure 2.

Panels $b$ and $c$ show three-hour excerpts of magnetograms from BAS LPM M81, Antarctica, and Paamiut (FHB), Greenland, respectively. The shaded region in each panel, from 0530 to 0800 UT, highlights the large magnetic perturbations observed at both stations, and the red arrows indicate the times of the only substorm onsets occurring within 3 hours prior to the MPE interval. 


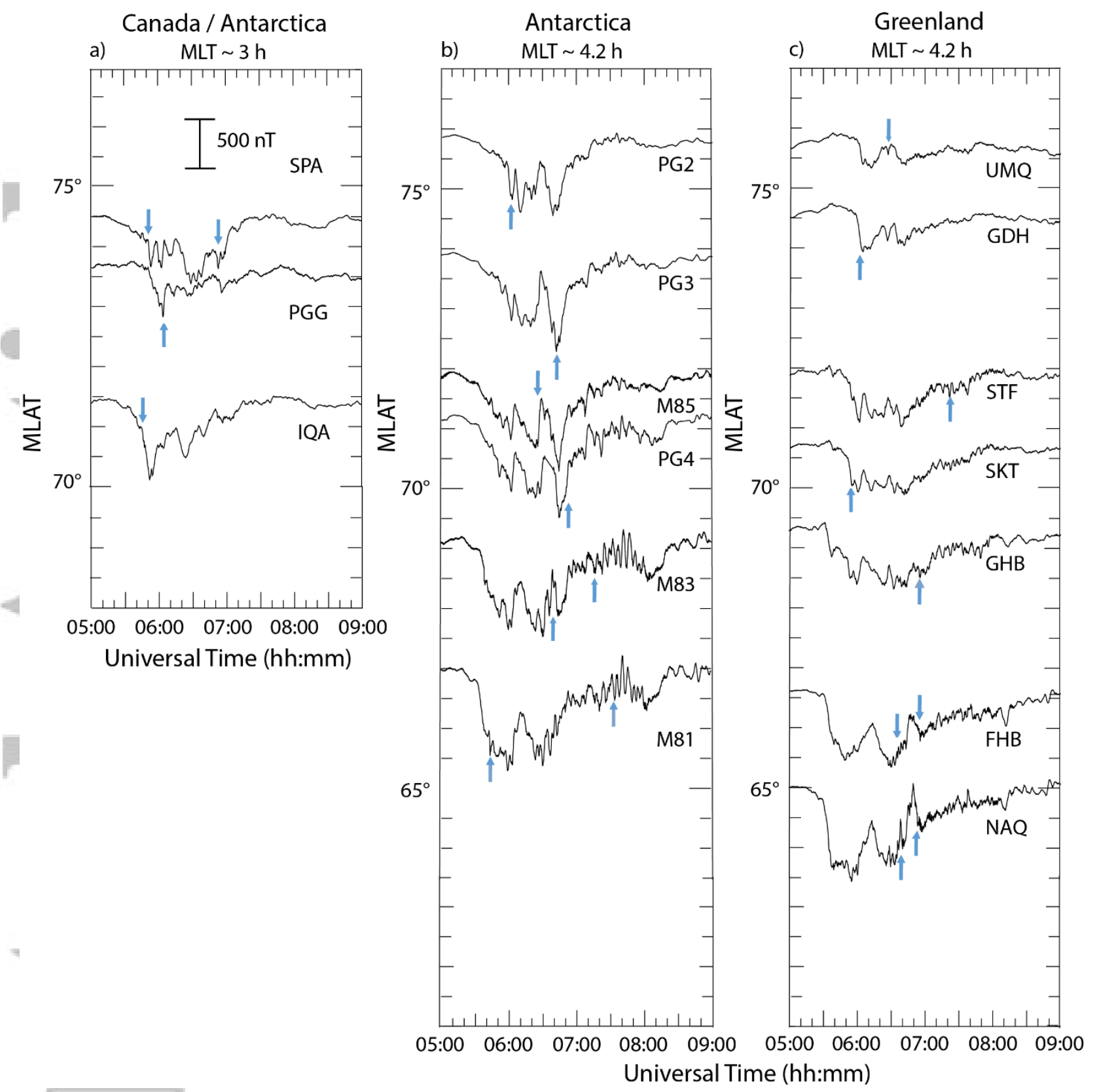

Figure 12. Four-hour excerpts of Bx component (north-south) magnetograms for May 13, 2015, as in Figure 3. a) SPA, PGG, and IQA, b) PG2, PG3, M85, PG4, M83, and M81, and c) UMQ, GDH, STF, SKT, GHB, FHB, and NAQ. Blue arrows_indicate the strongest MPEs at each station. 


\section{May 13, 201515133 05:30 - 08:00 UT}

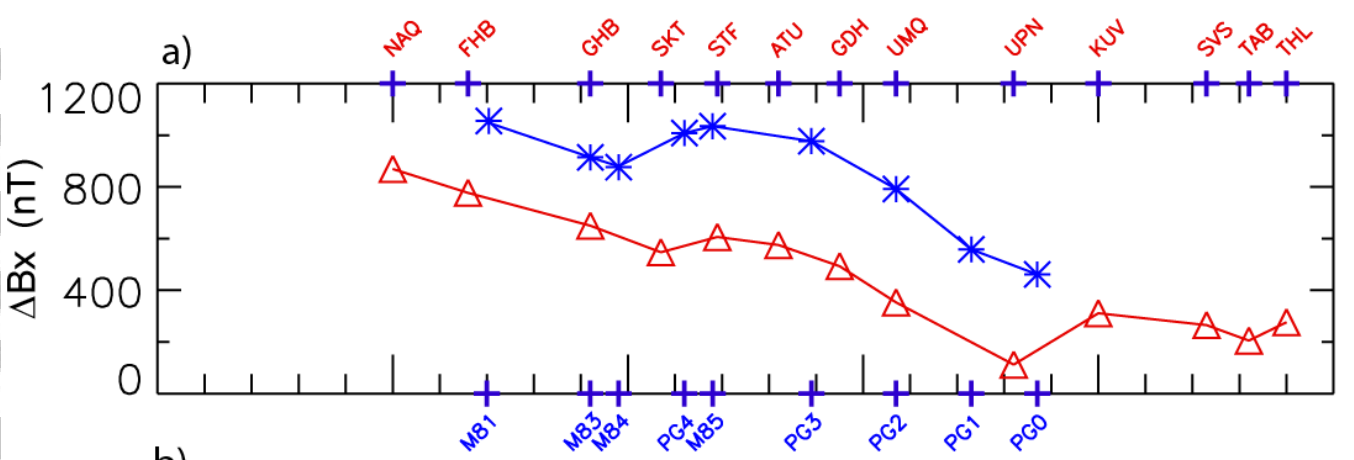

b)

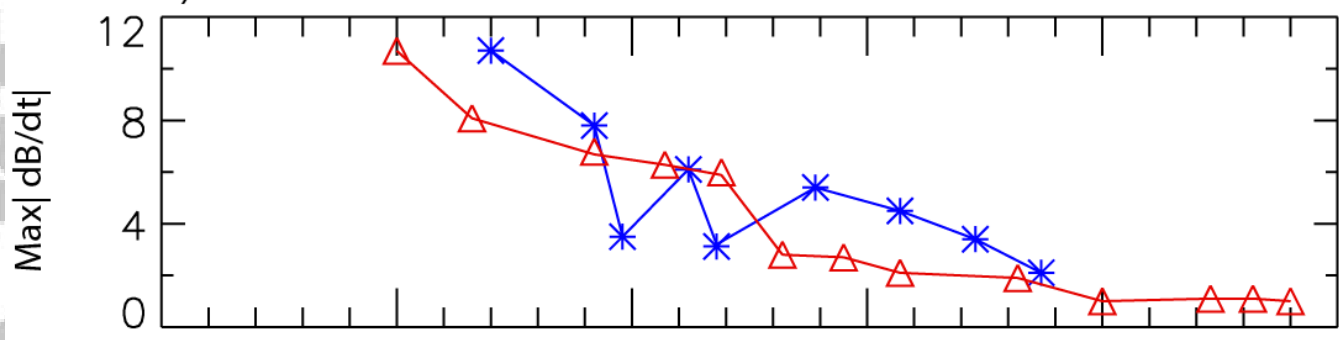

c) AMIE Model Conductances

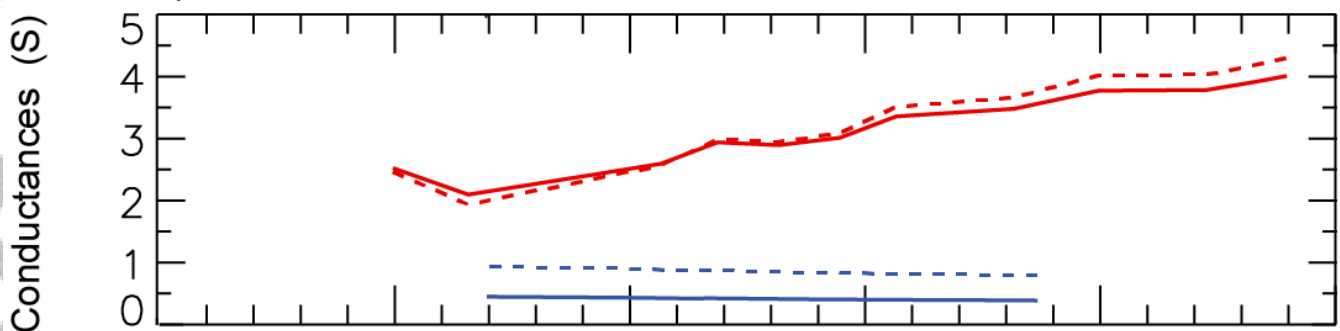

d) AMIE Model plus Ovation Prime Model Conductances

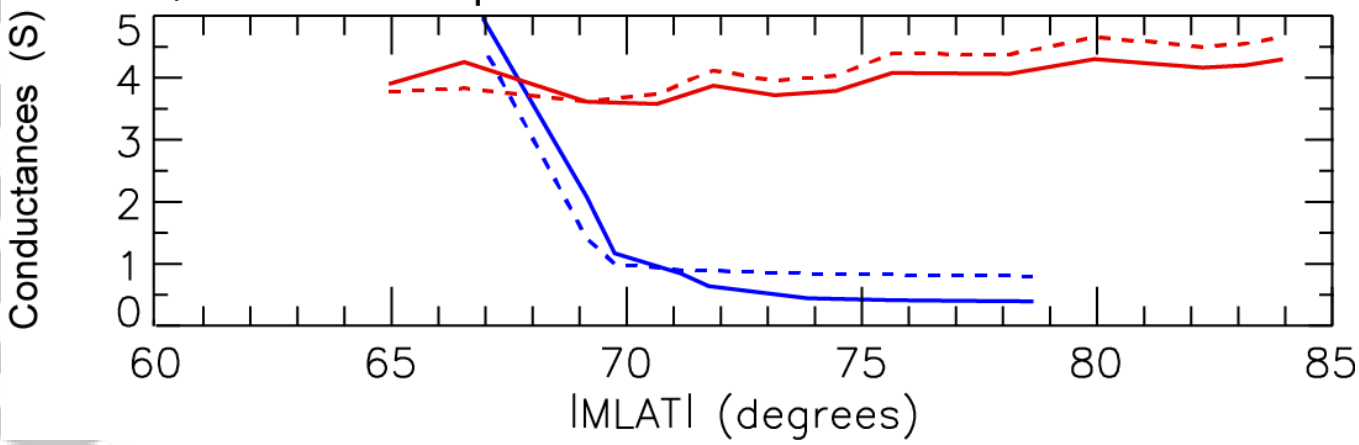

Figure 13. Plots of the perturbation amplitude $\Delta \mathrm{Bx}$ (panel a), the maximum derivative in any component (panel b), and two models of the ionospheric Pedersen and Hall conductances (panels c and d), as a function of magnetic latitude as in Figure 4, for the MPEs from 0530 to 0800 UT May 13, 2015. Solid lines denote Pedersen conductances $\left(\Sigma_{P}\right)$ and dashed lines Hall conductances $\left(\Sigma_{H}\right)$. 
DMSP F17 SSUSI LBH Short + Long Auroral Images May 13, 2015

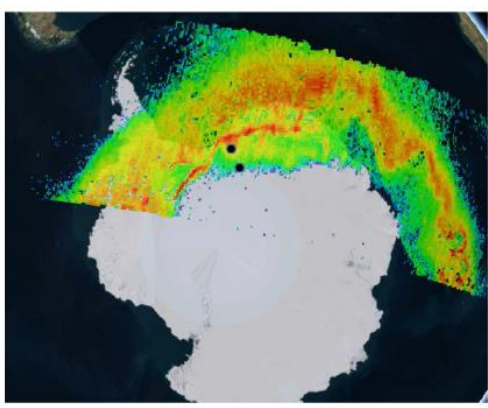

a: 0028 UT

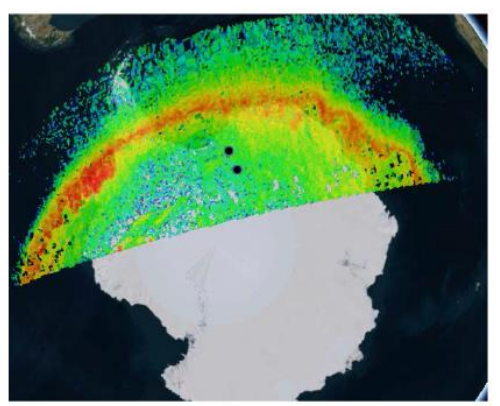

b: 0210 UT

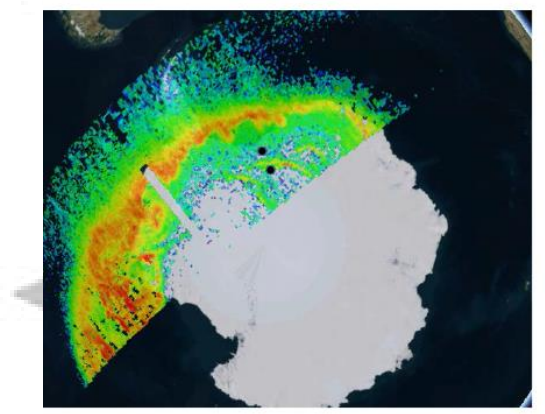

c: 0352 UT

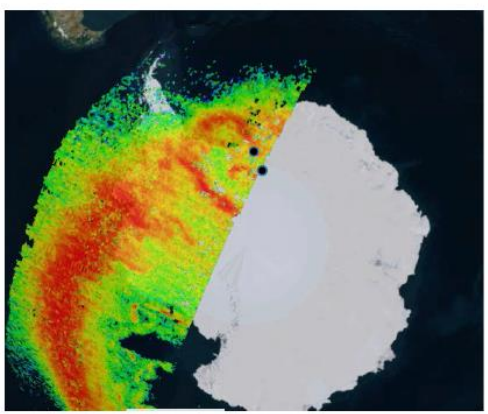

d: 0534 UT

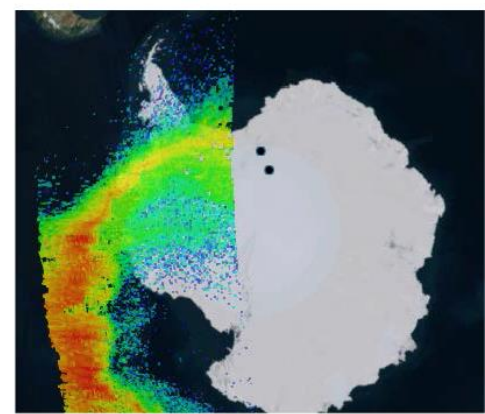

e: 0716 UT

Figure 14. Auroral images from the DMSP SSUSI imager during five successive passes of DMSP F17 over the Southern hemisphere on May 13, 2015. Each image shows the sum of the LBH short and LBH long ultraviolet bands, superposed on an outline map of Antarctica. The black dots in each image indicate the locations of BAS LPM M81 and M83. The time tag shown below each image is the UT time (in decimal hours) when the highest magnetic latitude pixel was imaged. 
a) DMSP F18

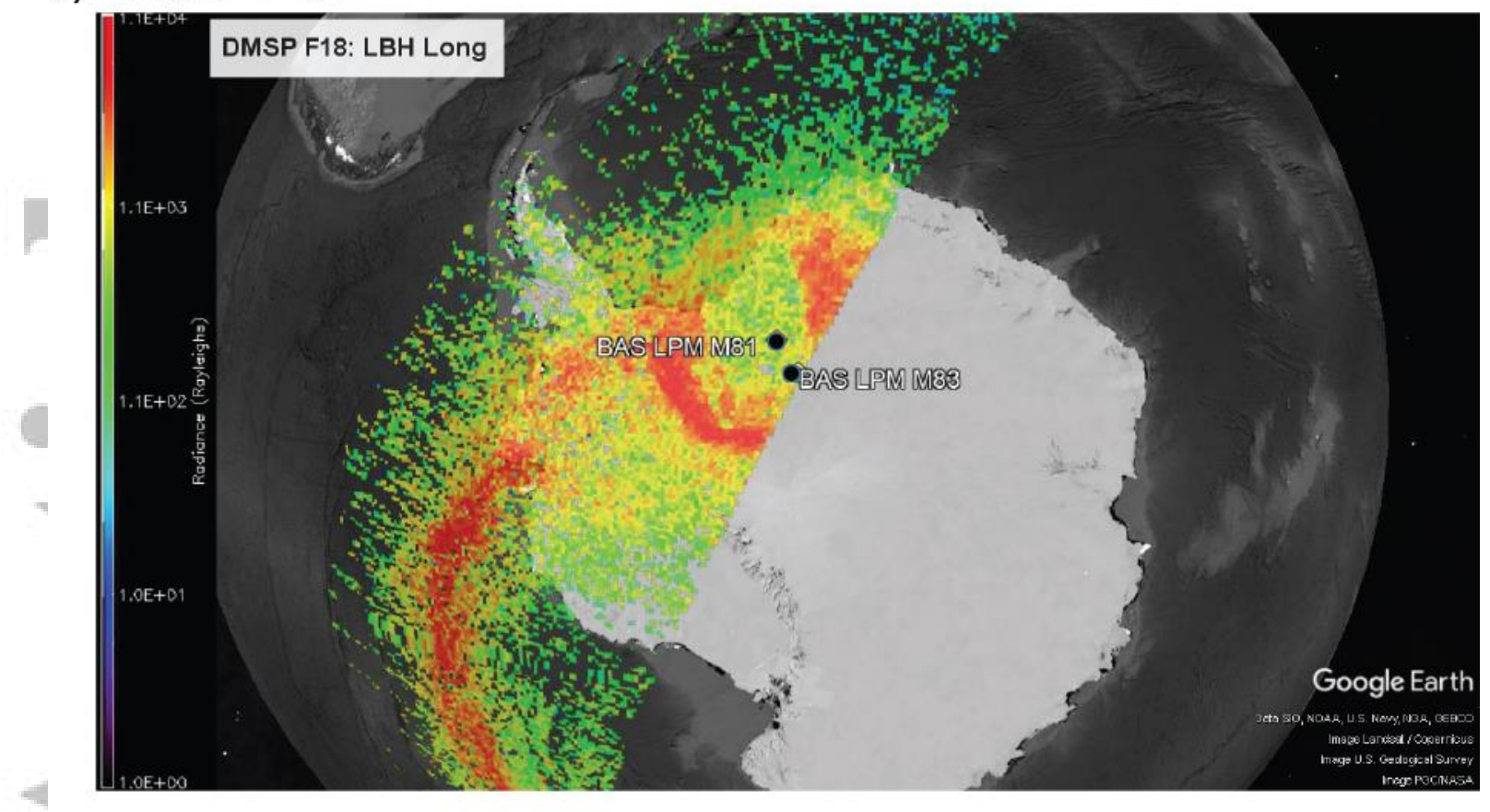

b) DMSP F19

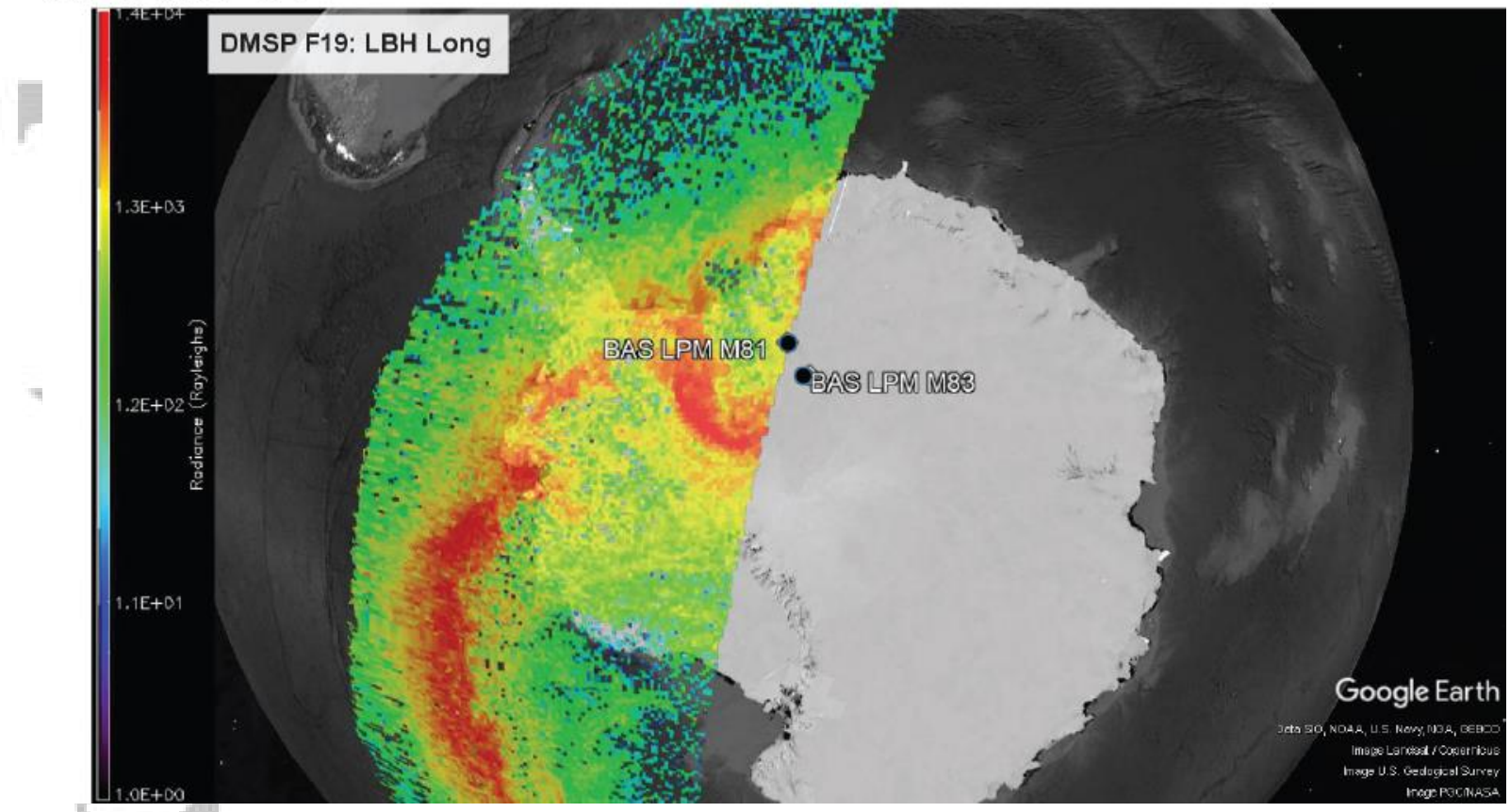

Figure 15. Auroral images in the LBH long band from the DMSP SSUSI imager from a) F18, at 5.94 h UT, and b) F19, at 5.89 h UT, respectively, on May 13, 2015. The black dots in each image indicate the locations of BAS LPM M81 and M83. 

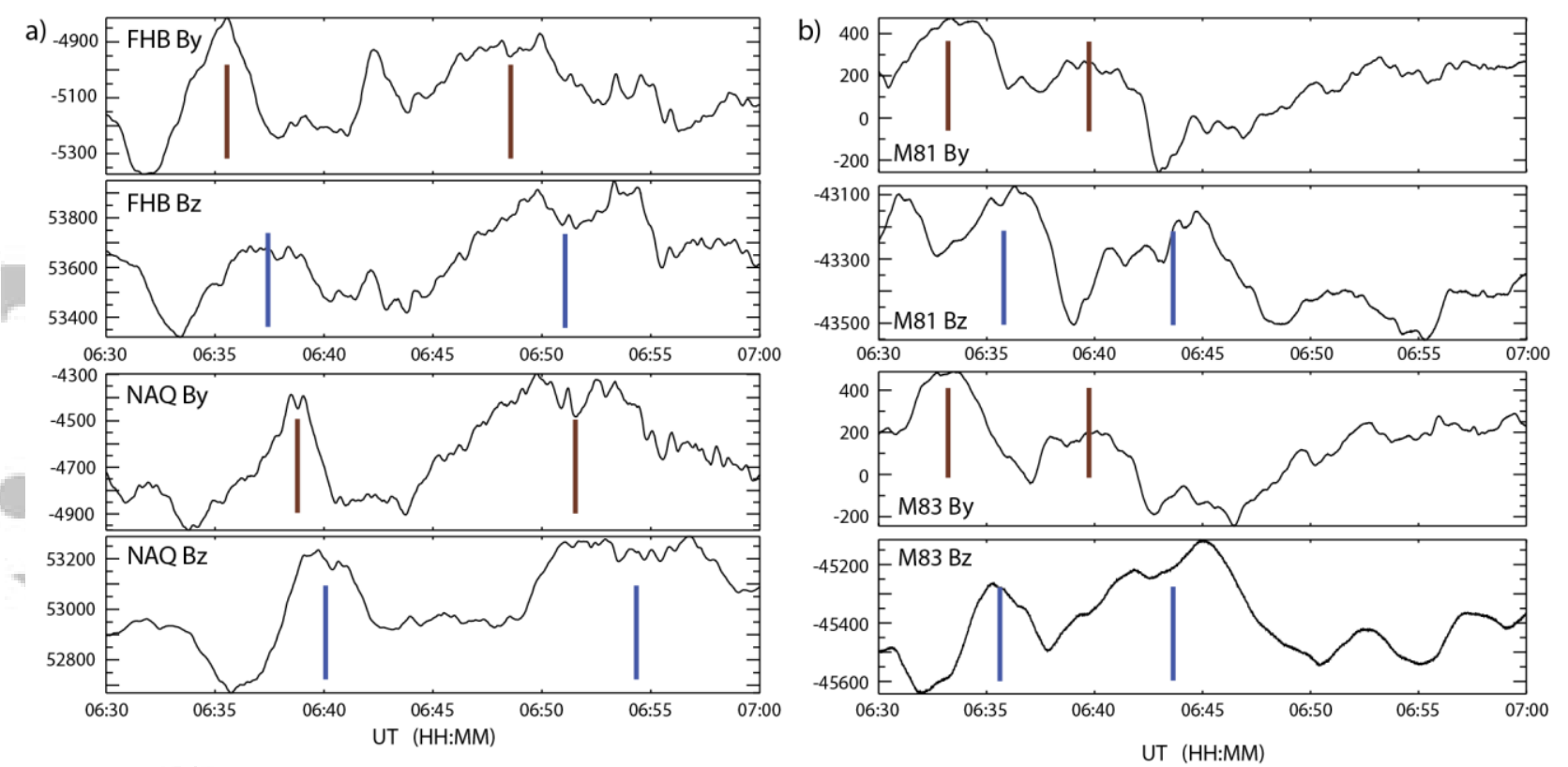

Figure 16. Plots of By and Bz component data from a) Greenland stations FHB and NAQ, and b) Antarctic stations M81 and M83 from 0630 to 0700 UT on May 13, 2015. The approximate times of two maxima in By at each station are indicated by the vertical red bars, and the corresponding maxima in $\mathrm{Bz}$ are indicated by vertical blue bars. 